UNIVERSIDADE DE SÃO PAULO

FACULDADE DE ECONOMIA, ADMINISTRAÇÃO E CONTABILIDADE DEPARTAMENTO DE ECONOMIA PROGRAMA DE PÓS GRADUAÇÃO EM ECONOMIA

\title{
Não é só um jogo: futebol como canal para a violência
}

Bernardo Ostrovski

Orientador: Prof. Dr. Raphael Bottura Corbi

São Paulo - Brasil 
Prof. Dr. Vahan Agopyan

Reitor da Universidade de São Paulo

Prof. Dr. Fábio Frezatti

Diretor da Faculdade de Economia, Administração e Contabilidade

Prof. Dr. José Carlos de Souza Santos

Chefe do Departamento de Economia

Prof. Dr. Ariaster Baumgratz Chimeli

Coordenador do Programa de Pós-Graduação em Economia 


\section{BERNARDO OSTROVSKI}

\section{Não é só um jogo: futebol como canal para a violência}

Dissertação apresentada à Faculdade de Economia, Administração e Contabilidade da Universidade de São Paulo como requisito parcial para a obtenção do título de Mestre em Ciências.

Orientador: Prof. Dr. Raphael Bottura Corbi

Versão corrigida

(versão original disponível na Faculdade de Economia, Administração e Contabilidade)

São Paulo - Brasil

2019 
Ficha catalográfica

Elaborada pela Seção de Processamento Técnico do SBD/FEA com os dados inseridos pelo(a) autor(a)

Ostrovski, Bernardo

Não é só um jogo: futebol como canal para a violência / Bernardo Ostrovski - São Paulo, 2019.

$44 \mathrm{p}$.

Dissertação (Mestrado) - Universidade de São Paulo, 2019.

Orientador: Raphael Bottura Corbi

1. Violência. 2. Futebol. 3. Mercado de apostas. 4. Regressão de Poisson. I. Universidade de São Paulo. Faculdade de Economia, Administração e Contabilidade. II. Título. 


\section{Agradecimentos}

Aos meus familiares. Em especial ao meu pai, Vinício, e ao meu cão, Gum, que estiveram presencialmente comigo durante todo o período do mestrado e foram meus pilares.

Ao Fluminense, por ser minha fonte de alívio emocional durante todo o período.

Aos meus amigos da UFRJ, em especial aos do "E ai,". Ao Hugo, Gil, Issa e Gabshow pelos churrascos, bares e chamadas de vídeo. Ao Poke e ao Pedro por compartilharem a mesma trajetória desde 2012.I, sendo essenciais para meu desenvolvimento na pós. À Laura, por toda ajuda mútua e companheirismo que tivemos durante a maior parte do curso, além do suporte emocional incrível que me forneceu em momentos importantes.

Aos colegas e amigos da pós, em especial Bruno, Denise e Rapha. Aos meus amigos do Mestrado. Ao Ahmad, Clara, Dani, Dornelas, Fabinho, Felipe, Igor, Johnny, Menon e Vinícius por todos estudos na salinha, bandejões, bares e ajuda ao longo do curso. Ao Matheus, pessoa incrível que se tornou um irmão durante essa caminhada e foi essencial para o resultado final.

Ao Zé por toda a parceria em São Paulo. À Isadora por ter se tornado uma amiga incrível para mim.

Aos professores que tive na USP e me agregaram valores. Ao Raphael, Mauro e Marcos pelas contribuições incríveis para esse trabalho. À Paula, Maria Dolores e Denisard pela oportunidade de trabalhar como monitor. Às turmas que tive oportunidade de ser monitor e que me fizeram crescer.

Ao Rolando, Rudi e Viviane por terem sido professores incríveis na minha graduação, sendo responsáveis por grande parte do meu interesse acadêmico. Se cheguei até aqui, a semente foi plantada lá atrás por vocês.

Por fim, à Fundação Instituto de Pesquisas Econômicas (FIPE) e ao Conselho Nacional de Desenvolvimento Científico e Tecnológico (CNPq) pela concessão da Bolsa de Pesquisa que muito me auxiliou a realizar essa pesquisa. 
"Be strong when things fall apart" (Blink-182, Please Take Me Home, 2001). 


\section{Resumo}

Este trabalho estuda o impacto de choques emocionais induzidos por resultados de jogos de futebol entre 2006 e 2016 no Brasil no comportamento violento dos indivíduos. Assume-se que o risco de violência pode ser modelado como função dos resultados das partidas. A hipótese chave é de que condicionando pelas probabilidades de vitória atribuídas aos times antes dos jogos, dadas pelos mercados de apostas, os resultados das partidas podem ser interpretados como aleatórios. Utiliza-se o fato de que torcidas de times de futebol do Brasil estão bem espalhadas ao longo dos municípios do país (e não apenas restritas ao estado de origem do time) para captar a proporção de pessoas atingidas por choques emocionais causados por partidas de futebol em determinado dia. O choque emocional é construído pela diferença entre a proporção de pessoas no município atingidas por choques positivos e a proporção atingida por choques negativos. Considera-se um choque o resultado da partida que foi muito diferente do previsto pelo mercado de apostas. O resultado encontrado indica que cada ponto percentual a mais no número de pessoas recebendo um choque negativo em determinado município eleva o número esperado de mortes por agressão em $0,08 \%$. A análise extensiva do modelo indica que o efeito é mais intenso para óbitos masculinos, principalmente àqueles ocorridos na rua. $\mathrm{O}$ número de mortes femininas ocorridas em casa aumenta de forma significante diante de choques negativos.

Palavras-chave: Economia do Crime. Violência. Futebol. Mercado de apostas. Regressão de Poisson. 


\begin{abstract}
This project studies the impact of emotional shocks induced by the results of brazilian soccer games in the period from 2006 from 2016 in the violent behavior of individuals. I assume the risk of violence being a function of the soccer games results. The key hypotesis is that conditional on the implied probabilities given by betting markets before the game, the actual results can be seen as random. I use the fact of soccer clubs distribution along the country being very spread, not only concentrated in the local state of the club (as happens in the NFL distribution of supporters) so I can mesure the proportion of people being affected by emotional shocks induced by soccer games in a given day. The emotional shock is given by the difference between the amount of individuals affected by positive shocks and the amount affected by negative shocks. I consider a schock when the result of the match differs from the predicted by the beting markets. The baseline result indicates that each 1 p.p. in the number of individuals receiving negative shocks in a given municipallity elevates the expected number of deaths caused by agressions in $0.08 \%$. The model extension analysis indicates that the effect is more intensive for men death, mainly the ones occuring in the streets. The number of women deaths occuring at home elevates significantly when a negative shock occurs.
\end{abstract}

Keywords: Crime Economics. Violence. Soccer. Betting market. Poisson regression. 


\section{Sumário}

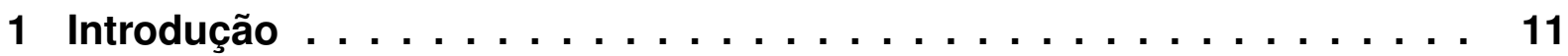

2 Revisão de Literatura . . . . . . . . . . . . . . . . . . . . . . 15

2.1 Esportes e Violência . . . . . . . . . . . . . . . . . . . . . . . 15

2.2 Economia do Crime . . . . . . . . . . . . . . . . . . . . 17

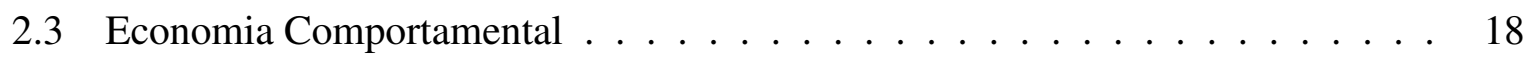

3 Dados e Metodologia . . . . . . . . . . . . . . . . . . 21

3.1 Base de Dados . . . . . . . . . . . . . . . . . . . . . 21

3.1 .1 Medindo Violência . . . . . . . . . . . . . . . . . . . 21

3.1.2 Resultados dos Jogos de Futebol e Mercados de Apostas . . . . . . . 23

3.1.3 Descrição de Dados de Torcidas . . . . . . . . . . . . . . . 26

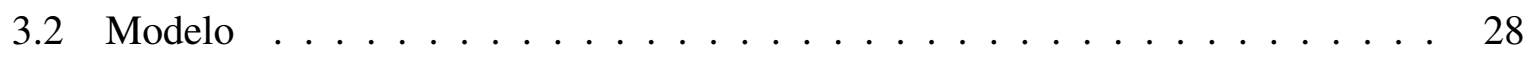

3.2.1 Modelo de Perda de Controle . . . . . . . . . . . . . . . . . . 28

3.2 .2 Modelo Econométrico _ . . . . . . . . . . . . . . . . . 30

4 Resultados . . . . . . . . . . . . . . . . . . . 33

4.1 Especificação Principal . . . . . . . . . . . . . . . . . . . . 33

4.2 Robustez e Extensões . . . . . . . . . . . . . . . . . . . . 33

4.2.1 Heterogeneidades: Gênero e Local . . . . . . . . . . . . . . . . 33

4.2 .2 Morbidade . . . . . . . . . . . . . . . . . . 35

4.2.3 Teste Placebo - Outras Causas de Óbitos . . . . . . . . . . . . . . . . 36

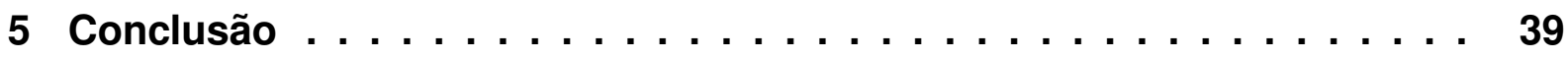

Referências $\ldots \ldots \ldots \ldots \ldots \ldots \ldots \ldots \ldots \ldots \ldots \ldots \ldots \ldots \ldots$ 



\section{Introdução}

A violência no Brasil é um dos maiores problemas do país, com índices chegando a patamares altíssimos. Em 2013 o país esteve com uma taxa de $25.2^{1}$ homícidios por 100.000 habitantes ( $18^{\mathrm{a}}$ no mundo) e mais de 50.000 homicídios por ano $\left(1^{\circ}\right.$ no mundo). Em um ranking de 2016 das 50 cidades mais violentas no mundo, feito pela ONG mexicana Seguridad, Justicia y Paz, ${ }^{2}$ o Brasil aparece com incríveis 21 cidades na lista. Se restringirmos para apenas metrópoles (cidades com mais de 250.000 habitantes), o Brasil possuí 32 das 50 cidades mais violentas. ${ }^{3}$ Esse não é apenas um problema brasileiro, já que nesse mesmo ranking, 43 das 50 cidades com mais homicídios estavam localizadas na América Latina, além de 8 dos 10 países com as maiores taxas de violência estarem localizados na mesma região. Sabe-se que muitas características socioeconômicas nesses países são parecidas, tais como a enorme desigualdade de renda, baixo nível educacional e elevadas taxas de corrupção, o que pode ajudar a explicar o fato deles terem índices de criminalidade tão altos.

O futebol no Brasil tem enorme influência na vida dos indivíduos. Cerca de $81 \%$ dos brasileiros demonstram algum interesse pelo esporte e $42 \%$ se declaram "superfãs"4, sendo que metade desses últimos declaram que costumam frequentar os estádios. A principal fonte de consumo para os fãs de futebol são as televisões ${ }^{5}$, que chegaram a ter quase $100 \%$ de alance na TV aberta e praticamente 199 milhões de telespectadores potenciais, no primeiro semestre de $2016 .^{6}$ Além disso, por ser um esporte tão popular e possuir times bem antigos (a grande maioria dos times utilizados neste trabalho já são centenários), existe uma facilidade em detectarmos jogos mais importantes, como os clássicos estaduais ou jogos eliminatórios, por exemplo. Além disso, não é só localmente que observamos brigas por conta de partidas de futebol, como noticiou o portal A Crítica em 24 de Agosto de 2017 ${ }^{7}$, quando torcedores de Flamengo e Botafogo se envolveram em briga na cidade de Manaus, enquanto a partida entre os dois times ocorria no Rio de Janeiro. Por isso, entende-se que as partidas de futebol são importantes canais de choques emocionais nos indivíduos ${ }^{8}$, merecendo uma atenção devida, conforme no trabalho de Corbi (2019), que utiliza o mesmo canal de jogos de futebol afetando o resultado de eleições e no resultado preliminar mostra que um aumento de um desvio padrão na proporção de indiví-

\footnotetext{
Se considerarmos Cerqueira (2013), essa taxa tende a ser maior ainda.
}

2 https://www.seguridadjusticiaypaz.org.mx/biblioteca/prensa/download/6-prensa/239-las-50-ciudades-masviolentas-del-mundo-2016-metodologia

3 https://www.economist.com/blogs/graphicdetail/2016/03/daily-chart-18

4 Isto é, de acordo com o IBOPE Repucom, a pessoa que se declara "muito interessada" por um determinado esporte

5 Cerca de 77\% a usam para acompanhar o time, segundo o IBOPE Repucom.

6 Alcance acumulado das transmissões do futebol na TV Globo.

7 Acesso em: https://www.acritica.com/channels/manaus/news/apos-briga-torcedores-do-flamengo-invadembar-e-atacam-botafoguenses-em-manaus

8 Para mais detalhes e estatísticas com relação à identificação do brasileiro com o futebol, ver http://www.iboperepucom.com/br/artigos/um-pais-que-respira-esportes/ 
duos recebendo choques emocionais reduz o número de votos do prefeito incumbente em cerca de 5.7 pontos percentuais.

Uma análise importante sobre a violência pode ser explicada a partir de choques emocionais negativos, que fazem com que o indivíduo altere seu comportamento (LOEWENSTEIN, 2000). Esses choques, apesar de serem rápidos e transitórios, podem ter consequências graves no comportamento das pessoas, alterando seu processo decisório. Nesse trabalho eu estudo o efeito de resultados de partidas de futebol sobre o comportamento dos indivíduos, usando dados de violência durante o período dos principais campeonatos de futebol do país. Para isso, emprego em uma utilidade do tipo "ganho-perda", que possui um ponto de referência (baseado em expectativas racionais do indivíduo sobre os possíveis resultados), para dizer o quão afetada pelo resultado da partida será o risco de violência por parte da pessoa Kőszegi e Rabin (2006).

Além disso, o mercado de apostas no futebol também é algo que, como consequência da grande audiência mundial ${ }^{9}$ pelo esporte, sempre foi bem organizado. ${ }^{10}$ Por isso, é possível utilizar dados de apostas de partidas dos principais campeonatos pelo Brasil para inferir ${ }^{11}$ sobre o resultado da partida, utilizando-o como o ponto de referência na utilidade de "ganho-perda". A hipótese principal é de que condicional as probabilidades de vitória antes da partida, o resultado da partida se torna aleatório, permitindo que se tenha um estimador não viesado para o efeito causal de uma derrota em relação a uma vitória.

Esse trabalho lida com dados (placares e probabilidades implícitas de vitória) de 7.867 partidas de futebol do período de Janeiro de 2006 até Dezembro de 2016, além das informações de homicídios através do Departamento de Informática do Sistema Único de Saúde (DATASUS). Usando dados de proporção de torcidas por municípios, condicionando o resultado das partidas às probabilidades implícitas de vitória anteriores a partida, dadas pelo mercado de apostas, encontrou-se uma relação inversa entre choques emocionais causados por partidas de futebol e mortes violentas. As evidências encontradas indicam que um aumento em cerca de 1 ponto percentual na proporção de indivíduos de um município recebendo choques negativos é suficiente para elevar em $0,08 \%$ o número esperado de óbitos por agressão. Como excluemse os locais das partidas, pode-se interpretar o resultado como um efeito emocional e não de aglomeração (que seria causado por brigas de torcidas no entorno do estádio ou próximo do município da partida). Quando olho para o sexo da vítima e o local da agressão, encontro que esse aumento de um ponto percentual nos choques negativos são responsáveis por aumentar em $0,2 \%$ o número esperado de mortes masculinas ocorridas na rua e aumentar em $0,58 \%$ o número esperado de óbitos femininos ocorridos em casa. Minha análise de placebo ajuda a visualizarmos que de fato os choques estão afetando apenas as mortes relacionadas às agressões,

9 Segundo a FIFA, na Copa do Mundo Masculina de Futebol, 3,2 bilhões de espectadores assistiram a competição.

10 Alguns trabalhos que exploram isso são: Sauer (1998); Debnath et al. (2003); Forrest, Goddard e Simmons (2005); Croxson e Reade (2014) e Nyberg (2014).

11 Conforme Card e Dahl (2011) e Corbi (2019) mostram, uma regressão dos resultados reais dos jogos sobre os resultados previstos é um previsor razoável e com um coeficiente estatisticamente diferente de zero. 
e que não existe uma correlação espúria entre as variáveis.

Recentemente, quatro trabalhos estudaram a relação entre futebol e violência. Primeiro, Gantz, Bradley e Wang (2006) olham para dados de violência familiar e ocorrência de partidas de futebol americano e encontram uma associação forte entre os dois. Depois, Rees e Schnepel (2009) estudam o efeito de jogos de futebol americano (a nível universitário) em taxas de vandalismo, roubos e delitos envolvendo álcool. Recentemente, Lindo, Siminski e Swensen (2018) analisaram a relação entre jogos de futebol americano universitário e violência sexual, notando que dias de jogos estão associados à maiores índices de incidentes desse tipo, principalmente no local da partida. Por fim, o que mais se aproxima do meu trabalho é o artigo de Card e Dahl (2011), onde os autores observam um efeito positivo na violência doméstica ocasionado por resultados negativos inesperados em partidas de futebol americano.

Esse estudo contribui para a literatura no sentido que investiga o efeito de choques emocionais em violência. Os trabalhos feitos até então não conseguem medir a distribuição de torcidas de forma intensiva (vide Card e Dahl (2011), que assumem que o estado local do time torce para o mesmo). Além disso, a literatura de Economia Comportamental analisada pela ótica de esportes é algo pouco explorada, então o trabalho aqui visa contribuir com mais resultados empíricos. Por fim, o tema de criminalidade no Brasil é algo bastante relevante e com alguns trabalhos de grande importância (SOARES, 2004; CERQUEIRA, 2014; CARNEIRO; SOARES; ULYSSEA, 2015; COSTA et al., 2016) e entende-se que existe certa importância para enriquecer o debate. 



\section{Revisão de Literatura}

\subsection{Esportes e Violência}

O principal estudo que segue é o de Card e Dahl (2011). Nele os autores avaliam o impacto de resultados de partidas $^{1}$ da liga estadunidense de futebol americano (NFL) em violência doméstica. A principal hipótese seguida é de que, condicional a um point spread (que será o análogo as probabilidades implícitas) dado pelo mercado de apostas, os resultados das partidas são exógenos para explicar mudanças no comportamento violento dos indivíduos. Foi encontrado um aumento de $10 \%$ em média nas ocorrências de violência quando o resultado do time da casa foi uma derrota inesperada (derrotas em que o time local era favorito a vencer por uma boa vantagem, dada exatamente pelo point spread citado antes). Esse aumento é ainda maior quando olhamos para jogos considerados mais "quentes" (clássicos locais, jogos eliminatórios ou jogos com números de algumas estatísticas mais elevados). Além disso, alguns testes de robustez ajudam a mostrar a consistência do modelo, usando o horário das ocorrências e dias sem partidas. Minha principal diferença com relação ao trabalho dos autores é explorar a intensidade das torcidas ao longo dos municípios do país, permitindo que eu capte um efeito emocional de forma separada ao efeito local da partida. Além disso, a medida de violência que se faz uso é mais geral do que a dos autores, então o meu resultado principal vai ser interpretado como violência, e não apenas violência doméstica.

Rees e Schnepel (2009) investigam a relação de jogos universitários de futebol americano e crime. Os resultados mostram que a cidade local das partida em que ocorre um jogo registram aumentos das taxas de assaltos, vandalismo, prisões por desordem e crimes relacionados ao abuso de álcool. ${ }^{2}$ Também é usada uma mensuração de "derrotas/vitórias inesperadas" mas de forma diferente a que é feita neste trabalho (usando os dados do mercado de apostas), já que os autores usam um ranking da imprensa para classificar o quão inesperado é o resultado. Entende-se que usar os odds do mercado de apostas sugere uma atualização mais fiel a realidade: por exemplo, um time pode ser o $1^{\circ}$ colocado mas ter perdido quatro partidas seguidas, o que fará com que se diminuam os odds do time para a próxima partida. ${ }^{3}$

Gantz, Bradley e Wang (2006) exploram a relação de violência familiar e ocorrência de jogos de futebol americano utilizando a transmissão na televisão como um canal para isso. Encontra-se um pequeno aumento no número de incidentes de violência doméstica na cidade em que ocorre uma partida da NFL. De forma parecida com o que é encontrado em Card e

1 Os autores usam apenas jogos em domingos pois estes são em média dois terços de todas partidas de uma rodada.

2 Neal e Fromme (2007) mostram que os dias de jogos de futebol americano universitário são aqueles em que os jovens mais bebem, até mesmo se comparado a feriados e datas que o consumo é mais alto.

3 Isso vai de encontro ao que Debnath et al. (2003) encontram. 
Dahl (2011), em dias de jogos com maior apelo emocional o aumento nas taxas é ainda maior. Uma descoberta interessante dos autores é o fato de que no dia da partida do Super Bowl (a final do campeonato da NFL) o aumento é ainda maior. Porém, isso é associado mais por esse dia se assemelhar a um feriado nacional (dias esses que possuem grande aumento nas taxas de ocorrência de violência doméstica) do que por ser um jogo de futebol americano. Esse resultado vai de encontro ao que Card e Dahl (2011) observam, mostrando um importante controle a ser feito no modelo.

Um estudo recente feito por Lindo, Siminski e Swensen (2018) explorou a relação entre eventos (no caso, jogos de futebol americano) que intensificam o número de festas universitárias podem elevar a ocorrência de crimes sexuais. Eles encontram que partidas de futebol americano universitário elevam os relatos de vítimas de 17 a 24 anos de estupro em 28\%. Esse efeito é muito mais forte e significante quando o jogo é local. Além disso, quando condicionam o resultado esperado da partida, seguindo a lógica do meu trabalho e de Card e Dahl (2011), encontram que vitórias inesperadas possuem efeito positivo em relatos de estupro ou crimes relacionados ao consumo de álcool, sendo que derrotas inesperadas não possuem efeitos. Isso pode diferir dos resultados dos dois trabalhos similares por conta do ambiente específico no qual é feita a análise, além de ser um forte efeito por aglomeração de estudantes em um local.

Eren e Mocan (2018) encontram que derrotas inesperadas de times de futebol americano universitário aumentam a duração de penas dadas por juízes americanos. Outro trabalho importante que utiliza esse esporte é o de Depetris-Chauvin, Durante e Campante (2018), que analisam o impacto das seleções nacionais de futebol nos indivíduos de países africanos. $\mathrm{O}$ resultado encontrado é de que vitórias dessas seleções tendem a aumentar a identificação nacional $^{4}$ dos indivíduos, além de uma ligeira redução em níveis de violência. Também ao nível de seleções nacionais, Bertoli (2017) encontra um efeito significativo de aumento de nacionalismo entre países no nível de conflitos entre os estados. Sendo assim, encontra-se bastantes resultados na literatura mostrando que os resultado das partidas de futebol exercem influência no comportamento individual.

Phillips (1983) analisa 6 anos de lutas (valendo prêmios) no campeonato estadunidense de pesos pesados e o impacto em homicídios. O resultado indica um aumento de cerca de $12 \%$ nas taxas de homicídios nos Estados Unidos da América. ${ }^{5}$ Posteriormente, Miller et al. (1991) reavaliam o trabalho feito e encontram resultados que se assemelham, mostrando que a televisão seria um importante canal para alimentar o comportamento violento.

Sachs e Chu (2000) não encontram nenhum efeito estatisticamente significativo de jogos de domingo da NFL em violência doméstica (apenas para Los Angeles), ainda que tenham encontrado um indício - que não pode ser testado mais a fundo por conta dos dados - de que em semanas de jogos eliminatórios e da final os índices tenham subido bastante. Porém, assim

$4 \quad$ Isto é, indivíduos passam a se identificar mais com o país do que com sua etnias.

5 Esse resultado se mostrou maior ainda quando a luta era mais divulgada. 
como dito pelos próprios autores, um estudo mais a fundo, que use mais de uma temporada e mais controles, deve resultar em resultados mais consistentes.

\subsection{Economia do Crime}

O ramo da economia que estuda criminalidade é algo bastante difundido hoje em dia mas que possuí origens no final dos anos 60, principalmente no trabalho de Becker (1968). ${ }^{6}$ $\mathrm{O}$ autor basicamente modela a escolha por crime como um bem da economia, mostrando que um indivíduo escolheria cometer um crime caso os benefícios do mesmo fossem maiores do que os custos. Além disso, a grande contribuição dele é de que políticas ótimas para combater o comportamento criminoso viriam a partir de alocações ótimas de recursos. Ou seja, seria possível um arcabouço econômico para ajudar a análise desse tipo de atividade.

Um trabalho bastante importante da literatura de Economia e Crime é o de Levitt (1995), que mostra um efeito positivo de aumento na força policial para reduzir as taxas de crime. Um grande problema envolvendo estudos de efeito de polícia em crime sempre foi a evidente simultaneidade entre as duas variáveis. $\mathrm{O}$ autor consegue observar um aumento da força policial durante épocas de eleição, algo exógeno a ocorrência de crimes. Assim, consegue-se obter uma boa estimativa do impacto (positivo) de polícia em reduzir crimes. ${ }^{7}$

Há bastante possibilidade de extensão para diferentes determinantes do crime. O primeiro estudo que traz isso é em Ehrlich (1973), com um modelo de decisão de participação em atividades ilegais. Os principais determinantes de criminalidade estudados são ${ }^{8}$ : desigualdade (CHIU; MADDEN, 1998; FAJNZYLBER; LEDERMAN; LOAYZA, 2002a; FAJNZYLBER; LEDERMAN; LOAYZA, 2002b); urbanização (GLAESER; SACERDOTE; SCHEINKMAN, 1996); educação (LOCHNER; MORETTI, 2001; LOCHNER, 2004); mercado de trabalho (RAPHAEL; WINTER-EBMER, 2001; GOULD; WEINBERG; MUSTARD, 2002); e políticas econômicas (FOLEY, 2011; CARNEIRO; SOARES; ULYSSEA, 2015).

Uma discussão que será retomada na parte metodológica diz respeito ao menor reportamento de crimes em países menos desenvolvidos, introduzida por Soares (2004). Assim, existiria um grande viés nas estimações envolvendo dados de relatórios policiais. Dois trabalhos brasileiros que servirão de apoio trabalham com proxies para contornar isso. Em Carneiro, Soares e Ulyssea (2015) os autores exploram a relação entre o choque de liberalização comercial brasileira da década de 1990 e o crime. Além desse, Costa et al. (2016) exploram uma descontinuidade de densidade para tentar avaliar mudanças por se atingir a maioridade penal no comportamento criminoso individual. Ambos trabalhos exploram o fato de que homícidios causados por mortes violentas podem servir de boas proxies da atividade criminal.

6 Outros trabalhos importantes também são os de Fleisher (1966), Stigler (1970) e Ehrlich (1973).

7 Alguns trabalhos parecidos que usam ataques terroristas como instumentos para o aumento de policiamento são os de Tella e Schargrodsky (2004), Klick e Tabarrok (2005) e Draca, Machin e Witt (2011).

8 Sem contar a enorme discussão sobre uso de força policial e crime, citados no parágrafo anterior e, esportes e crime, citados na subseção anterior. 
Por fim, muito da literatura brasileira de economia do crime se deve aos trabalhos de Cerqueira (2013) e Cerqueira (2014). No primeiro, o autor revela a grande quantidade de mortes violentas que não possuem sua causa determinada, mostrando que o sistema de produção de informações sobre óbitos havia enorme falha. Assim, no período de 1996-2010 o número de homicídios ocultos por ano no país seria de, em média, 8.600. No outro trabalho o autor revela importantes determinantes da atividade criminal, analisa a correlação entre dados captados pelo DATASUS e pela polícia, além de importante análise da relação entre armamento populacional e crime.

\subsection{Economia Comportamental}

Um importante fator que afeta a tomada de decisão dos indivíduos são choques emocionais provenientes de diferentes canais. Loewenstein (2000) argumenta que não são somente preferências $^{9}$ (como a teoria neoclássica acabou focando) que afetam a utilidade dos indivíduos mas também as emoções (ou a felicidade deles, por exemplo). Grande atenção deve ser dada aos chamados visceral factors (fatores viscerais), que, de acordo com Loewenstein (1996), são estados temporários em que os indivíduos se encontram, tais como fome, sede, desejo sexual, emoções ou dor, por exemplo. Esses fatores são caracterizados por serem algo prazeroso e que o indivíduo passe a dar muita atenção (mas por vias negativas) e afetarem desejos relativos a bens e ações. Assim, elementos do dia a dia, tais como uma partida de futebol, podem afetar as emoções individuais, levando as pessoas a se comportarem de maneira mais agressiva. Quando em certo estágio emocional, um indivíduo pode sacrificar grandes quantidades de bens que não são relacionados ao fator visceral para ter pouco de bens relacionado a ele (tais como um viciado em alguma droga). Assim, apesar dos fatores serem transitórios, os efeitos comportamentais que produzem são, a longo prazo, bastante impactantes no sentido individual e social.

Dessa forma, fica evidente que certos estudos, tais como o trabalho feito, devem incorporar alguns elementos psicológicos que serão relevantes para a análise econômica. ${ }^{10} \mathrm{~A}$ ideia é que devemos considerar um ponto de referência na utilidade do indivíduo (e não somente o nível de consumo), elaborado através de expectativas acerca do futuro e considerando o consumo passado (RABIN, 1998). Assim, indivíduos seriam maximizadores de utilidade dadas suas expectativas racionais com relação aos resultados, sendo essas expectativas dependentes de um comportamento antecipado. ${ }^{11}$ Em Kőszegi e Rabin (2006) vemos um modelo interessante que usa uma utilidade de "ganho-perda", que será usada por nós para associar resultados das parti-

9 Loomes e Sugden (1982) mostram que muitos outros importantes fatores deveriam afetar as escolhas individuais, o que passou desapercebido pela teoria tradicional. Fatores esses poderiam ser a capacidade dos indivíduos anteciparem certos sentimentos. Rabin (1993) elabora um modelo de jogos considerando comportamentos sociais diferentes do que as hipóteses da Teoria dos Jogos tradicional considera.

10 Elster (1998) traz uma discussão interessante acerca de emoções e como estas se relacionam a outros fatores, afetando nosso comportamento.

11 Existem alguns fatos estilizados acerca dessa dependência de um ponto de referência. Talvez o mais interessante, constatado desde Kahneman e Tversky (1979), é a aversão à perda: indivíduos dão mais importância a perder certa quantidade de um bem do que ganahr a mesma quantidade do mesmo bem. 
das de futebol em cima do ponto de referência. Os autores ainda argumentam que esse ponto de referência seria mais afetado pela expectativas do que pelo status quo, mostrando que será importante condicionar os odds da partida no modelo, isto é, se um indivíduo espera que seu time ganhe a partida, então uma derrota irá causar bastante impacto negativo em sua utilidade. Seguirá-se a mesma lógica usada por Corbi (2019), onde resultados inesperados em partidas de futebol afetam emocionalmente os indivíduos a votar, podendo levá-los a cometerem atos violentos. 



\section{Dados e Metodologia}

\subsection{Base de Dados}

\subsubsection{Medindo Violência}

Usarei dados de mortalidade (homicídios causados por agressões) e morbidade (internações totais) como proxies de crime. Esses dados são do DATASUS (Departamento de Informática do Sistema Único de Saúde), que é uma base de dados administrativa do Ministério de Saúde, disponível online, e contém informações detalhadas sobre as causas de óbito/internação de acordo com o CID-10 (Classificação Estatística Internacional de Doenças e Problemas Relacionados com a Saúde).

Os números de homicídios no Brasil são os mais altos do mundo e a taxa de homicídios é uma das mais altas. De acordo com Carneiro, Soares e Ulyssea (2015), a taxa de homicídios no país em 2010 é 2,5 vezes maior do que em 1980 e o número total de homicídios aumentou 5 vezes, de 10.000 para 50.000 ao ano. Além disso, há bastante dispersão das taxas através das regiões, principalmente entre Sul (mais baixa) e Nordeste (mais alta).

Os relatórios policiais no Brasil não são computados de forma a permitir uma comparação ao nível nacional, além de que pode existir uma diferença entre a qualidade dos dados de cada estado. Por isso, homicídios e agressões registrados no DATASUS serão a única maneira de computar dados de criminalidade que se estendem por municípios ao longo do tempo em todo o país de forma homogênea. Além disso, homicídios são estatísticas de crime mais confiáveis em países em desenvolvimento, pois existe um grande número de não-reportamentos de problemas menos sérios (SOARES, 2004). Ainda assim, Carneiro, Soares e Ulyssea (2015) mostram que os homicídios registrados pelo sistema de saúde são extremamente correlacionados com dados policiais de homicídios, crime contra indivíduos e crimes violentos contra propriedades. ${ }^{1}$

As categorias usadas para definir mortes violentas são as de X85 até Y09, seguindo a CID- $10^{2}$. As mortes por agressão representam cerca de $3 \%$ do total das mortes do período analisado. Usando dados de 2006 a 2016, podemos observar na Tabela 1 a taxa média diária de óbitos por 100.000 habitantes, além da mesma taxa para as internações totais, para algumas categorias específicas. Pode-se notar que a taxa para o período é de 0,021 mortes por 100.000 habitantes diariamente, em média. Além disso, nota-se que homens morrem um pouco mais do que mulheres, quando se olhando essa causa de óbito. Chama a atenção o fato de que homens morrem bem mais do que comparados as mulheres quando se tratando em mortes na rua, enquanto que

Ver Apêndice A em Carneiro, Soares e Ulyssea (2015).

2 Por exemplo, temos que a categoria X91 é definida como "Agressão por meio de enforcamento, estrangulamento e sufocação". 
mortes domésticas esse número é praticamente 50\%. O fato de algumas subcategorias não somarem 1 é por conta da perda informacional que ocorre em algumas variáveis (por exemplo, não há registrado em muitos casos qual que é o sexo do indivíduo).

Vê-se pela Tabela 3 abaixo quais que são as principais causas de morte dentro do contexto de mortes por agressão. É possível notar que dentre as mortes que tiveram causa por agressão são majoritariamente por armas de fogo ou objetos cortantes.

Tabela 1: Estatísticas descritivas de mortes por agressão e internações, 2006-2016 - Parte 1

\begin{tabular}{|c|c|c|}
\hline & Taxa diária (14:00-01:59) média por 100.000 habitantes & Proporção na subcategoria \\
\hline I. Óbitos por Agressão & & \\
\hline Dias de jogos & $\mathbf{0 , 0 2 1}$ & \\
\hline $\begin{array}{c}\text { Apenas dias de jogos quentes } \\
\text { A. Gênero }\end{array}$ & 0,022 & \\
\hline Sexo $=$ Masculino & 0,009 & 0,43 \\
\hline $\begin{array}{l}\text { Sexo }=\text { Feminino } \\
\text { B. Local }\end{array}$ & 0,008 & 0,38 \\
\hline Local $=$ Casa & 0,003 & 0,15 \\
\hline Local $=$ Hospital & 0,008 & 0,36 \\
\hline $\begin{array}{l}\text { Local }=\text { Rua } \\
\text { C. Rua, por sexo }\end{array}$ & 0,006 & 0,30 \\
\hline Sexo $=$ Masculino & 0,004 & 0,65 \\
\hline $\begin{array}{l}\text { Sexo }=\text { Feminino } \\
\text { D. Casa, por sexo }\end{array}$ & 0,002 & 0,33 \\
\hline Sexo $=$ Masculino & 0,001 & 0,45 \\
\hline $\begin{array}{l}\text { Sexo }=\text { Feminino } \\
\text { E. Dia da Semana }\end{array}$ & 0,001 & 0,37 \\
\hline Domingo & 0,022 & \\
\hline Sábado & 0,023 & \\
\hline Terça & 0,022 & \\
\hline Quarta & 0,017 & \\
\hline Quinta & 0,020 & \\
\hline II. Internações Totais & & \\
\hline Dias de jogos & 8,636 & \\
\hline $\begin{array}{c}\text { Apenas dias de jogos quentes } \\
\text { A. Gênero }\end{array}$ & 7,700 & \\
\hline Sexo = Masculino & 3,413 & 0,40 \\
\hline Sexo = Feminino & 5,222 & 0,60 \\
\hline
\end{tabular}

Nota: Elaboração própria. Fonte: DATASUS/SIM.

Tabela 2: Estatísticas descritivas de mortes por agressão e internações, 2006-2016 - Parte 2

\begin{tabular}{lcc}
\hline \hline Variável & Média & Desvio-Padrão \\
\hline Agressão Total & 0,0078 & 0,112 \\
Agressão Homem & 0,0054 & 0,094 \\
Agressão Mulher & 0,0017 & 0,047 \\
Agressão Casa & 0,0009 & 0,032 \\
Agressão Rua & 0,0030 & 0,065 \\
Agressão Homem Casa & 0,0005 & 0,025 \\
Agressão Homem Rua & 0,0025 & 0,059 \\
Agressão Mulher Casa & 0,0002 & 0,017 \\
Agressão Mulher Rua & 0,0046 & 0,024 \\
Morbidade Total & 5,7452 & 37,155 \\
Morbidade Homem & 3,4001 & 16,970 \\
Morbidade Mulher & 2,3443 & 16,971 \\
& \multicolumn{2}{c}{} \\
\hline \hline Elaboração própria. Fonte: DATASUS/SIM.
\end{tabular}


Tabela 3: Principais mortes por agressão

\begin{tabular}{lll}
\hline \hline Código CID-10 & Morte por: & \% das mortes por agressão \\
\hline X93 & Tiro por arma de fogo & 0,07 \\
X95 & Outros tiros de arma de fogo/arma não-identificada & 0,63 \\
X99 & Objeto afiado & 0,17 \\
Y00 & Martelos & 0,05 \\
- & Outros & 0,08 \\
\hline \hline
\end{tabular}

Nota: Elaboração própria. Fonte: DATASUS/SIM.

Podemos ver que mortes por agressões não são tão comuns ao longo da base através da Tabela 4. Quase 99, 5\% dos dias temos 0 registros de mortes por essa causa. Alguns números chamam atenção, como o fato de que $92 \%$ das mortes por agressão são com vítimas do sexo masculino (enquanto que se comparando todas as outras causas, homens são $54 \%$ das vítimas).

Tabela 4: Frequência de Agressões ao nível de município-dia

\begin{tabular}{ll}
\hline \hline $\begin{array}{l}\text { Total de } \\
\text { agressões }\end{array}$ & Percentual \\
\hline 0 & 99,31 \\
1 & 0,58 \\
2 & 0,08 \\
3 & 0,02 \\
4 & 0,01 \\
$5-10$ & $<0,01$ \\
& \\
\hline \hline Nota: Elaboração própria. Fonte: DATASUS/SIM.
\end{tabular}

\subsubsection{Resultados dos Jogos de Futebol e Mercados de Apostas}

Meu trabalho usará dados dos três principais campeonatos nacionais (Série A, Série B e Copa do Brasil), sendo o Campeonato Brasileiro Série A o principal deles. O formato de disputa é de turno e returno, onde cada time enfrenta duas vezes os outros adversários (um jogo em seu estádio e outro jogo no estádio do adversário), com duração de Maio até Dezembro. No total dos 38 jogos, o time que somar mais pontos é declarado campeão. Além disso, existe um sistema de rebaixamento e promoção entre a Série A e a Série B, onde os quatro últimos (primeiros) da Série A (B) são rebaixados (promovidos) para a Série B (A). Na base final são 7.687 partidas de futebol para o período compreendido entre 2006 a 2016.

Os mercados de apostas sobre jogos de futebol do Brasil são organizados por trocas internacionais onlines e funcionam com apostas em odds fixados. Cada indivíduo aposta junto a outros, normalmente com uma comissão sendo cobrada, escolhendo um dos três possíveis resultados (vitória, empate, derrota) para algum time. Esses resultados ficam associados a um $o d d$, que é o inverso de uma probabilidade implícita para aquele resultado. Por exemplo, suponha que uma vitória do Fluminense sobre o Flamengo possuí um odd de 1,25 e um indivíduo aposta $\mathrm{R} \$ 100,00$ nesse resultado. Então, em caso de vitória do Fluminense o indivíduo ganha 
$\mathrm{R} \$ 125,00$ e caso contrário (empate ou derrota), perde $\mathrm{R} \$ 100,00$. Nesse exemplo, a probabilidade implícita de vitória do Fluminense fica em torno de $80 \%$ (já que $1,25^{-1}=4 / 5=0,80$ ).

A hipótese chave é de que condicional as probabilidades implícitas de vitória anteriores ao jogos começarem os resultados das partidas são aleatórios. Portanto, as previsões sobre resultados de jogos de futebol do Brasil, feitas pelos mercados de apostas precisam ser consistentes. Uma análise econômica sobre mercados de apostas em eventos esportivos por Sauer (1998) concluí que esses mercados são eficientes. Além disso, eles conseguem absorver bem a informação pública disponível (FORREST; GODDARD; SIMMONS, 2005) e fazem isso com a informação bem próxima ao início do jogo (DEBNATH et al., 2003). Também existem evidências de que os odds de aposta são bons previsores de jogos de futebol na Inglaterra (CROXSON; READE, 2014; NYBERG, 2014). Por fim, se verifica que ponderar os odds de diferentes agências de aposta é uma forma de cancelar ineficiências individuais feitas pelos bookmakers (CORBI, 2019).

Os dados disponíveis são de resultados e médias de probabilidades implícitas de vitória para cada time para 7.867 jogos de futebol de todas as principais competições nacionais ${ }^{3}$ do período de 2006 a 2016. A Tabela 5 mostra a frequência dos resultados efetivos das partidas e as probabilidades implícitas associadas a eles. Fica evidente que os times mandantes das partidas possuem vantagem (ganham metade dos jogos) e que as probabilidades implícitas se aproximam bem do resultado. A diferença de médias pode ser explicada pela grande diferença nos desvios-padrões, já que resultados de partidas tendem a serem muito mais voláteis do que as previsões individuais.

Tabela 5: Resultado das Partidas de Futebol Observados e Previstos

\begin{tabular}{lll}
\hline \hline Resultado & Real (d.p.) & Previsto (d.p.) \\
\hline Mandante & $0,502(0,500)$ & $0,477(0,132)$ \\
Empate & $0,255(0,436)$ & $0,272(0,031)$ \\
Visitante & $0,242(0,428)$ & $0,270(0,117)$ \\
\hline \hline & $\begin{array}{c}\text { Nota: Resultados das partidas de futebol previstos pelas probabilidades } \\
\text { dos mercados de apostas. Como elas somam mais do que um, os } \\
\text { resultados foram normalizados. Elaboração própria. }\end{array}$
\end{tabular}

Na Figura 1 vemos que os odds de apostas são bons previsores da diferença de gols (gols do time da casa menos gols do time visitante) dos jogos. No eixo da abcissa, temos a diferença entre as probabilidades de vitória e derrota do mandante atribuídas pelo mercado de apostas (sendo assim, quanto mais à direita for um ponto, maior o favoritismo do time mandante). Uma regressão do diferencial do placar no diferencial de probabilidades de vitória retorna um coeficiente de 2.10 e um desvio-padrão de $0.064\left(R^{2}=0.12\right)$. Os pontos verdes à direita (vermelhos à esquerda) do gráfico são partidas em que o time da casa é previsto a vencer (perder). Diremos que um time é previsto a ganhar quando a probabilidade implícita de vitória é maior do 
que 50\%. Um jogo será considerado "próximo"quando nenhum time for previsto de ganhar a partida.

Figura 1: Diferença no Placar e Probabilidades Implícitas

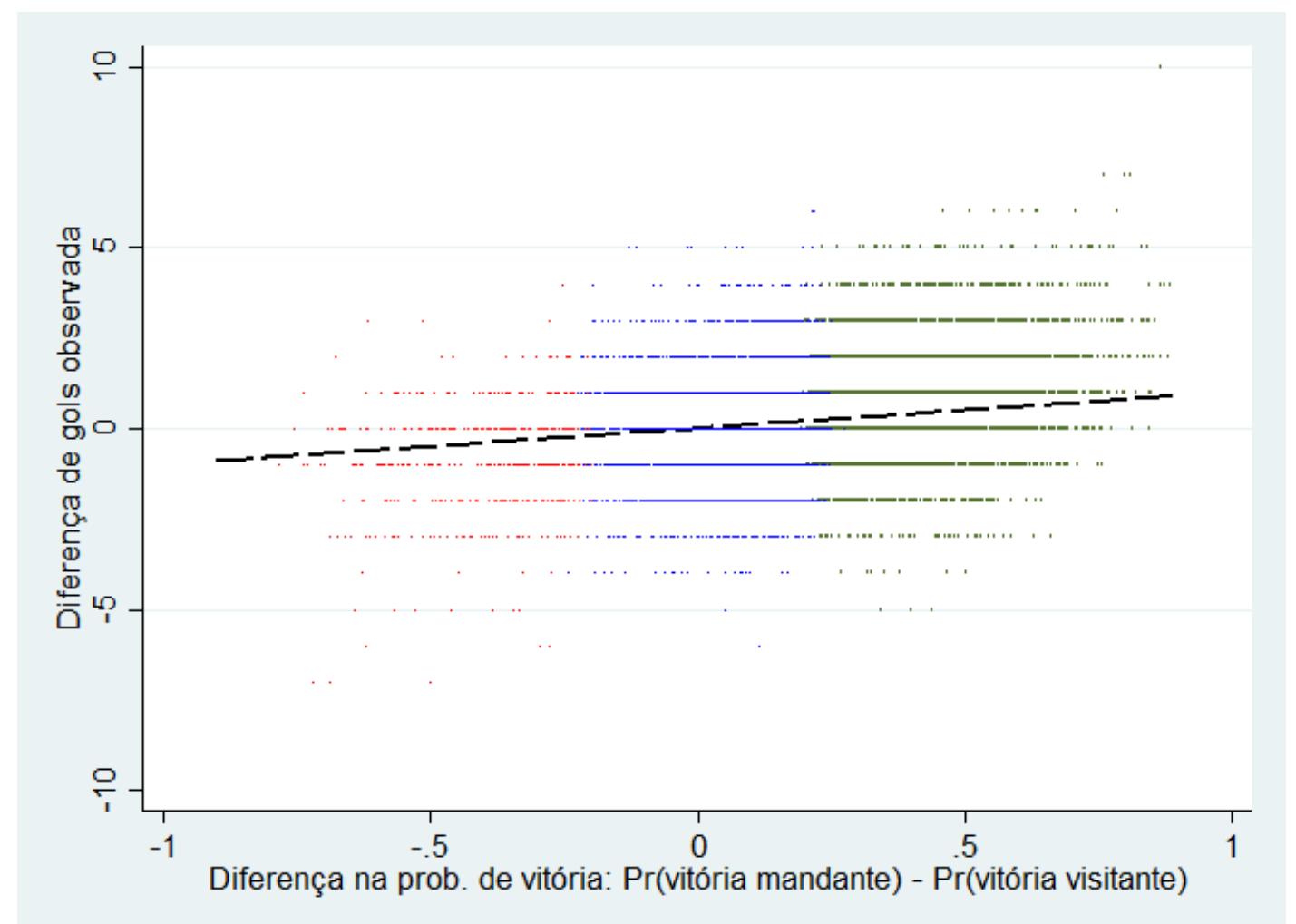

Nota: Elaboração própria.

A Tabela 6 abaixo mostra a frequência de dia da semana em que os jogos ocorrem. Fica evidente que a grande maioria das partidas ocorrem aos Domingos, Sábados ou Quartas. As análises serão feitas comparando-se os cinco dias da semana com maior frequência de partidas, e nos respectivos horários, indo na mesma direção do estudo de Card e Dahl (2011) ${ }^{4}$.

Tabela 6: Frequência de jogos por dia da semana

\begin{tabular}{lcc}
\hline \hline Dia da Semana & Frequência & Proporção \\
\hline Domingo & 2.030 & 0,26 \\
Terça-Feira & 1.012 & 0,13 \\
Quarta-Feira & 1.645 & 0,21 \\
Quinta-Feira & 516 & 0,07 \\
Sábado & 2.062 & 0.26 \\
\hline Total & 7.867 & 1 \\
\hline \hline \multicolumn{2}{l}{ Nota: Valores para Segundas e Sextas-Feira omitidos, pois não } \\
serão usados esses dias nas regressões. Elaboração própria.
\end{tabular}

Podemos ver pela Tabela 7 que jogos aos finais de semana costumam ser mais cedo do que os de meio de semana. Sendo assim, faremos um recorte de tempo que começa às 14:00 de

$4 \quad$ A única diferença aqui é que no estudo dos autores só se trabalha com Domingos, visto que esse dia da semana representa quase a totalidade das partidas, enquanto que no jogos do Brasil isso fica mais dissolvido entre os dias. 
um dia e acaba às 01:59 do dia seguinte, de maneira a garantir que os jogos de finais de semana e os de meio de semana sejam considerados dentro do horário.

Tabela 7: Frequência de jogos por dia da semana e horário da partida

\begin{tabular}{lllllllll}
\hline \hline & & \multicolumn{7}{c}{ Hora inicial da partida } \\
Dia da semana & $13 \mathrm{~h}-15 \mathrm{~h}$ & $16 \mathrm{~h}$ & $17 \mathrm{~h}$ & $18 \mathrm{~h}$ & $19 \mathrm{~h}$ & $20 \mathrm{~h}$ & $21 \mathrm{~h}$ & $22 \mathrm{~h}$ \\
\hline Domingo & 0,03 & $\mathbf{0 , 4 8}$ & $\mathbf{0 , 1 5}$ & $\mathbf{0 , 2 5}$ & 0,08 & $>0,01$ & $>0,01$ & 0 \\
Terça-Feira & 0,01 & 0,02 & $>0,01$ & 0,01 & $\mathbf{0 , 4 0}$ & $\mathbf{0 , 1 3}$ & $\mathbf{0 , 4 2}$ & $>0,01$ \\
Quarta-Feira & 0,01 & 0,04 & 0,04 & $>0,01$ & $\mathbf{0 , 2 8}$ & $\mathbf{0 , 1 6}$ & $\mathbf{0 , 2 7}$ & 0,19 \\
Quinta-Feira & 0,01 & 0,03 & 0,04 & 0,01 & $\mathbf{0 , 3 1}$ & $\mathbf{0 , 2 5}$ & $\mathbf{0 , 3 4}$ & 0,01 \\
Sábado & 0,02 & $\mathbf{0 , 3 5}$ & 0,10 & $\mathbf{0 , 3 1}$ & 0,08 & 0,02 & $\mathbf{0 , 1 2}$ & $>0,01$ \\
\hline Freq. & 176 & 1.773 & 434 & 1.269 & 1.316 & 595 & 1.997 & 307 \\
Prop. & 0,02 & 0,26 & 0,08 & 0,16 & 0,18 & 0,08 & 0,18 & 0,04 \\
\hline \hline
\end{tabular}

Note: Número de partidas por dia da semana por horário (arredondado) de início da partida. Por exemplo, se um jogo começou às $21: 45$, consideraremos o horário como $21 \mathrm{~h}$. Elaboração própria.

\subsubsection{Descrição de Dados de Torcidas}

Como muitos times do país são bastante populares regional ou nacionalmente, outro aspecto a ser explorado é o alcance de cada time pelas regiões do país. Usando dados de 60 milhões de "curtidas" em páginas oficiais de 64 times de futebol brasileiro ${ }^{5}$, a parir do Mapa das Torcidas (uma parceria entre o Facebook e o site de notícias esportivas globoesporte.com), é possível mapear a proporção de torcedores de cada time por municípios ${ }^{6}$. Como a rede social reúne cerca de 122 milhões de usuários no Brasil, é razoável de se imaginar que essa medida de alguma noção geral da distribuição de torcidas ${ }^{7}$. A Figura 2 exibe um mapa com os dois times mais curtidos por municípios. Podemos ver a ampla dominância de Flamengo e Corinthians ao longo do país, com algumas potências estaduais ou regionais dominando certas áreas, como o São Paulo, Cruzeiro, Vasco da Gama e Grêmio.

Dessa maneira, será possível ganhar uma variável importante na estimação do efeito causal de choques inesperados em cima de criminalidade, pois poderei explorar a variação na quantidade de torcedores de cada time dentro dos municípios. Por exemplo, pela Figura 3 podemos ver os locais que esperamos serem afetados por choques emocionais causados por jogos do Vasco, São Paulo, Cruzeiro ou Grêmio. No caso, quanto mais forte a tonalidade da cor, maior é a proporção de curtidas de torcedores sobre o total de curtidas naquele município. Portanto, um choque inesperado em uma partida do Vasco deve causar mais impacto nos índices de crime

5 São eles: todos os participantes das Séries A, B e C de 2017, exceto o Macaé, além de Portuguesa, Campinense, América-RN, Treze-PB e Sergipe.

6 Os dados são para municípios com mais de 5000 habitantes e foram coletados no dia 07/02/2018. Um torcedor é contabilizado quando curte uma página oficial do clube, verificada pelo Facebook, e possuí sua cidade local inserida na rede social. Existe a possibilidade de um mesmo indivíduo curtir duas ou mais páginas de clubes distintos, mas o número de pessoas que faz isso é pequeno. Mais informações estão disponíveis em https://globoesporte.globo.com/futebol/noticia/como-foi-feito-o-mapa-de-curtidas-das-torcidas-dobrasil-no-facebook.ghtml

7 O único ponto a ser levantado é com relação a distribuição de torcida da Chapecoense, que sofreu enorme aumento após a tragédia de 2016. Para evitar distorções, utilizei os dados de 2015 para esse clube. Mias informações sobre os dados de 2015 em: http://globoesporte.globo.com/futebol/noticia/2015/09/como-foi-feito-omapa-de-curtidas.html 
Figura 2: Distribuição Geográfica da Base de Torcidas

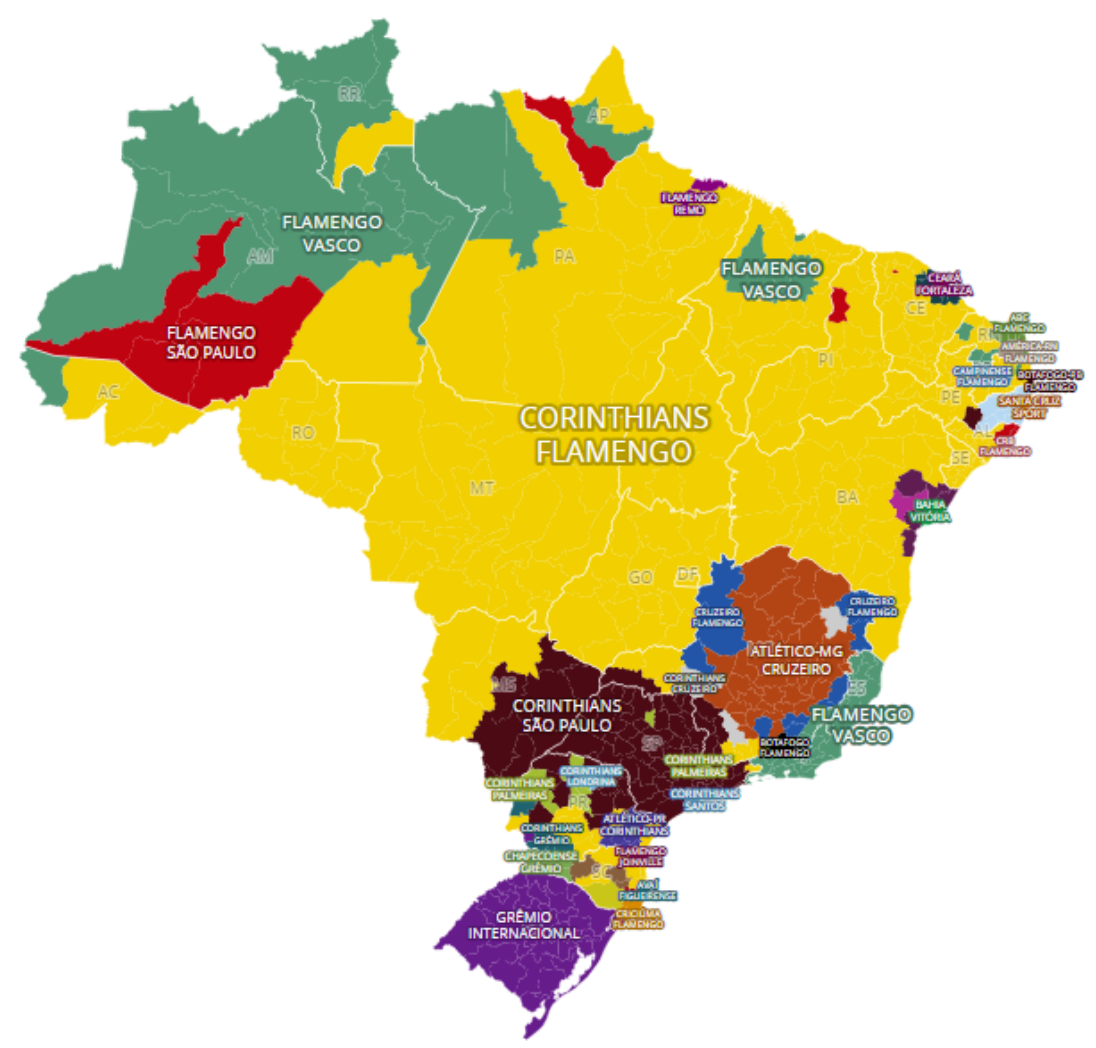

\begin{tabular}{|c|c|c|c|}
\hline & Mais curtidos & $N^{\circ}$ de municipios & Populaçāo da área \\
\hline ㅇ & Corlinthlans e Famengo & 2238 & 55.664 .002 \\
\hline - & Corinthlans e SaO Paulo & 904 & 48.862740 \\
\hline - & Flamengo e vasco & 303 & 29.810 .462 \\
\hline - & Atetico-MG e Cruzelro & 439 & 12033.357 \\
\hline$\bullet$ & Gremlo e Internacional & 516 & 11.527 .000 \\
\hline ๑ & Banla e vitorla & 17 & 4.057 .029 \\
\hline - & Santa Cruz e Sport & 14 & 3.914 .317 \\
\hline e & Corlmthlans e Sport & 109 & 3.600 .660 \\
\hline - & Atletico-PR E Corinthlans & 33 & 3.574 .444 \\
\hline - & Ceard e Fortaleza & 9 & 3.563 .797 \\
\hline - & Flamengo e Remo & 17 & 2522304 \\
\hline - & Cruzelro e Flamengo & 147 & 2161.626 \\
\hline 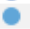 & Corinthlans e Santos & 12 & 1.873.528 \\
\hline - & Banla e Corinthlans & 62 & 1.778 .784 \\
\hline - & ABC e Flamengo & 36 & 1.767 .552 \\
\hline - & Flamengo e sao paulo & 51 & 1.764 .445 \\
\hline 6 & Corinthlans e Paimeiras & 112 & 1.546 .748 \\
\hline ? & CRB e Flamengo & 11 & 1.256 .092 \\
\hline - & Botafogo-PB e Flamengo & 7 & 1.132286 \\
\hline - & Banla e Famengo & 23 & 1.074 .405 \\
\hline ○ & Avar e Flguerense & 9 & 900.878 \\
\hline 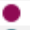 & Flamengo e jolnville & 11 & 942.556 \\
\hline - & Corinthlans e Gremlo & 55 & 925.423 \\
\hline - & Chapecoense e Gremlo & 90 & 920.785 \\
\hline 6 & Corlinthlans e Cruzeiro & 35 & 857.183 \\
\hline - & Ceara e Corinthlans & 30 & 831.068 \\
\hline - & Cricluma e flamengo & 32 & 802.154 \\
\hline - & Corlinthlans e Londrina & 7 & 797.024 \\
\hline & Botafogo e Ramengo & 33 & 776.228 \\
\hline 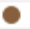 & Chapecoense e Flamengo & 54 & 622.937 \\
\hline - & Campinense e Flamengo & 8 & 526238 \\
\hline - & Amerlca-RN e Ramengo & 43 & 472430 \\
\hline - & Flamengo e Gremlo & 18 & 202.478 \\
\hline & Figueirense e Flamengo & 5 & 25.009 \\
\hline
\end{tabular}

das regiões Norte, Nordeste e no eixo Rio-Espírito Santo, enquanto que um choque por conta de uma partida do Grêmio deve gerar uma variação mais forte nos índices da região Sul e no Mato Grosso. 
Figura 3: Distribuição de Curtidas do Vasco da Gama, São Paulo, Cruzeiro e Gremio
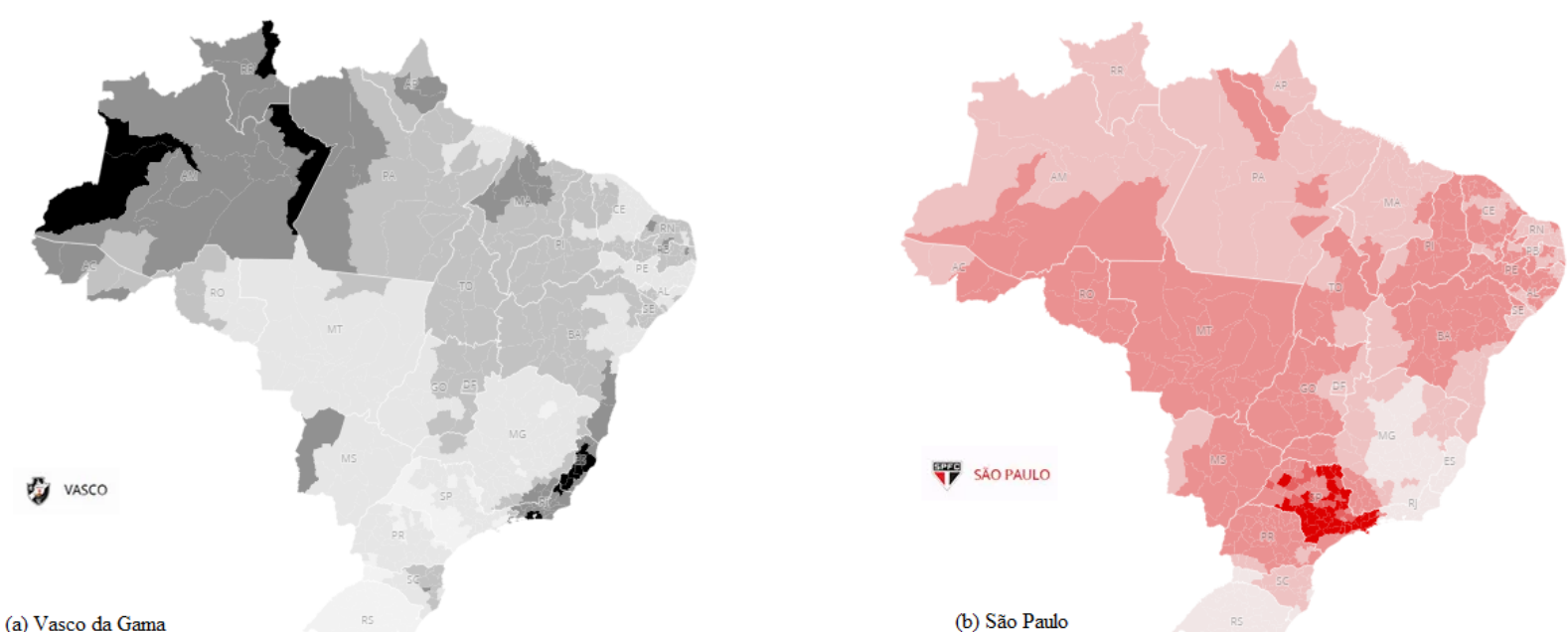

(b) São Paulo

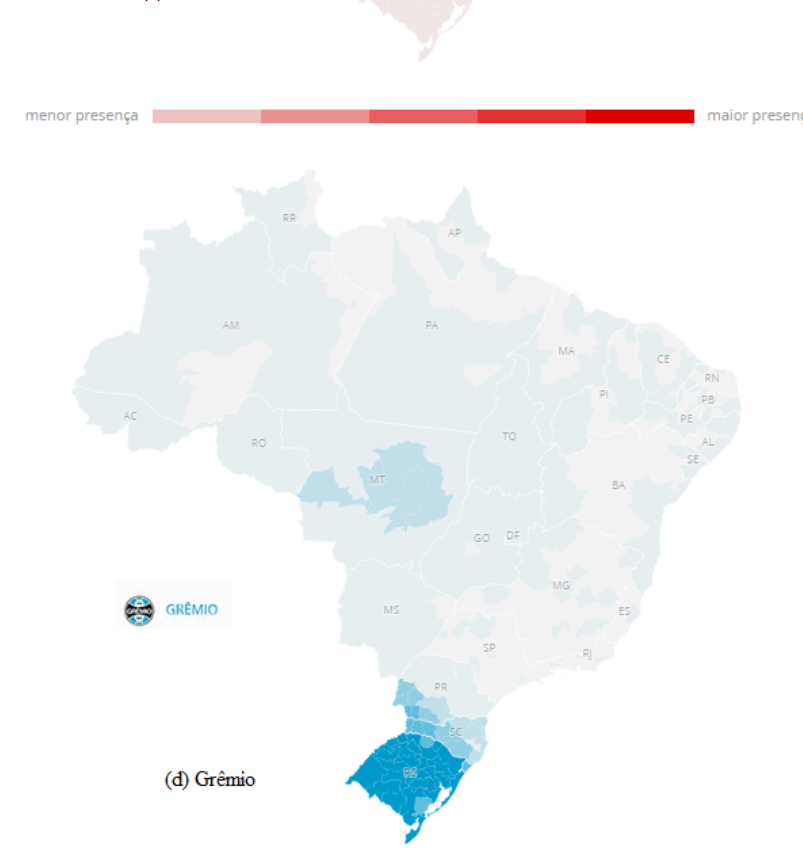

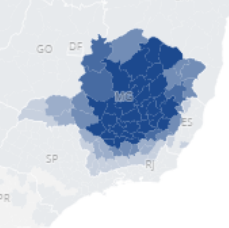

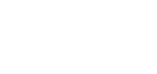

\subsection{Modelo}

Apresentarei aqui de forma simplificada o modelo que estará por trás do estudo. Minha hipótese é de que o resultado de partidas de futebol afetam o comportamento dos indivíduos através de uma função de utilidade do tipo ganho-perda, como já explicada anteriormente. Seguiremos de forma muito parecida a Card e Dahl (2011) e Corbi (2019).

\subsubsection{Modelo de Perda de Controle}

Essa subseção descreverá o modelo teórico que serve de pano de fundo para a relação causal que se mostra no trabalho. Suponha que a probabilidade $v \geq 0$ de um indivíduo cometer 
um ato violento (por isso "perda de controle") possa ser escrita como uma função linear de choques emocionais ocasionados por jogos de futebol. Seja $y$ uma variável binária que assume valor 1 caso o time vença a partida e 0 caso perca. Ainda, suponha que $\mathbb{E}[y]=p$, tal que

$$
v=\bar{v}-\mu(y-p),
$$

onde $\mu$ é a utilidade ganho-perda ${ }^{8}$. Iremos supor que essa utilidade é linear:

$$
\begin{aligned}
& \mu(y-p)=\alpha(y-p), \text { se } y<p \\
& \mu(y-p)=\beta(y-p), \text { se } y>p .
\end{aligned}
$$

Ou seja, em (3.2) estamos falando de uma derrota e em (3.3) estamos falando de uma vitória. Como visto pela bibliografia de Economia Comportamental, há um consenso de que o efeito marginal de uma perda é maior do que o de um ganho (por conta da aversão à perda), o que implicaria em $\alpha>\beta$. Assim, podemos expressar a probabilidade de um indivíduo cometer um ato violento como função da probabilidade do time da casa vencer a partida:

$$
\begin{gathered}
v^{D}(p)=\bar{v}+\alpha p, \text { se } y=0 \text { (derrota) } \\
v^{V}(p)=\bar{v}-\beta(1-p)=(\bar{v}-\beta)+\beta p, \text { se } y=1 \text { (vitória). }
\end{gathered}
$$

Figura 4: Risco de violência decorrente de uma derrota ou vitória

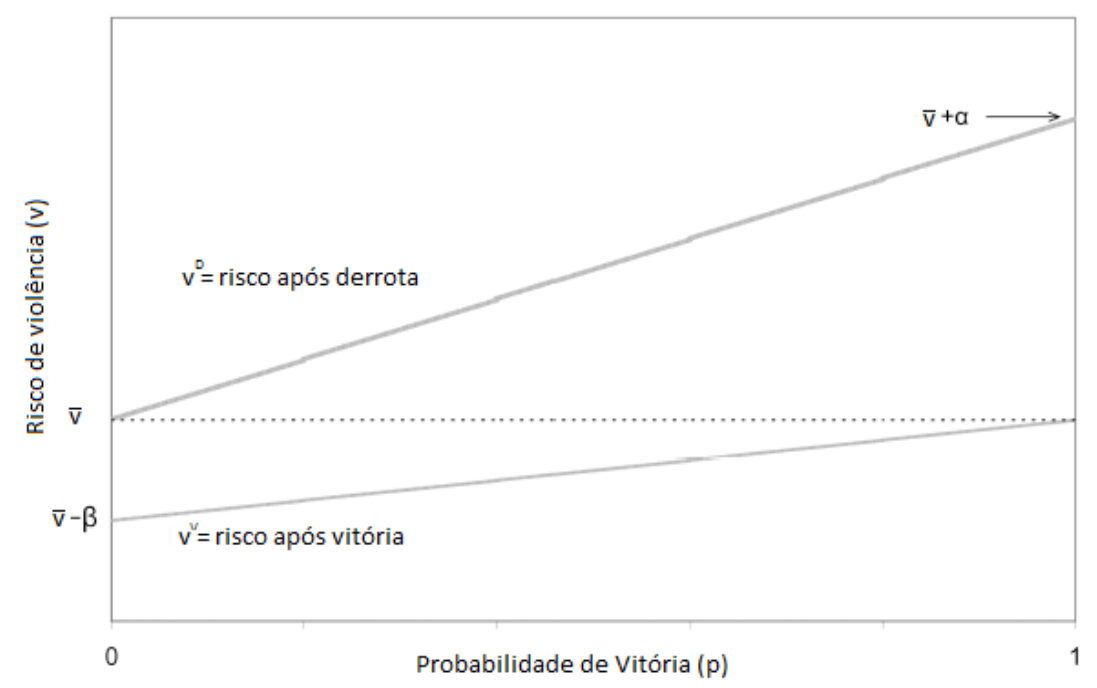

Nota: Imagem traduzida de Card e Dahl (2011).

8 Tal como em Kőszegi e Rabin (2006). 
Podemos ver pela Figura $4^{9}$ que quando $p$ está bem próximo de 0 os indivíduos já esperam um resultado negativo com relação à partida. Nesses casos, os riscos de violência são dados por $\bar{v}$ em (3.4) e $\bar{v}-\beta$ em (3.5). Essas duas situações seriam as "melhores" dentro de cada contexto de derrota ou vitória do time. $\operatorname{Com} p>0$, qualquer derrota se torna minimamente inesperada, sendo atribuída como algo negativo na utilidade do indivíduo. Note que quanto mais o indivíduo atribuí probabilidade de vitória maior é o risco de violência, independentemente do resultado da partida. $\mathrm{O}$ caso mais extremo se dá quando $p \approx 1$ e o resultado da partida é uma derrota: nesse caso, temos uma derrota totalmente inesperada, fazendo com que a dispersão do ponto de referência da utilidade seja (de forma negativa) bem alta.

\subsubsection{Modelo Econométrico}

Meu modelo seguirá um modelo de Regressão Poisson para o número de incidentes violentos (morbidade ou mortalidade) reportados pela autoridade de saúde. Como especificado na seção de dados, as três variáveis indicadoras de previsão do resultado do time $k$ no dia $t$ serão definidas por:

$$
\begin{gathered}
p_{k, t}^{v i t}=\left\{\begin{array}{l}
1, \text { se } P r_{t}(k \text { vencer })>0.5 \\
0, \text { caso contrário; }
\end{array}\right. \\
p_{k, t}^{\text {der }}=\left\{\begin{array}{l}
1, \text { se } P r_{t}(k \text { perder })>0.5 \\
0, \text { caso contrário }
\end{array}\right. \\
\text { e }
\end{gathered}
$$

Dessa forma, podemos definir as variáveis de choque emocional geradas pelo resultado da partida do time $k$ no dia $t$ :

$$
\begin{aligned}
& \operatorname{pos}_{k, t}=\left[v i t_{k, t}+e m p_{k, t}\right] p_{k, t}^{d e r}+v i t_{k, t} p_{k, t}^{e m p} \\
& n e g_{k, t}=\left[d e r_{k, t}+e m p_{k, t}\right] p_{k, t}^{v i t}+d e r_{k, t} p_{k, t}^{e m p}
\end{aligned}
$$

onde vit, emp e der são variáveis indicadoras de uma vitória, empate ou derrota do time. Analogamente, $p_{k, t}^{v i t}, p_{k, t}^{e m p}$ e $p_{k, t}^{\text {der }}$ são as variáveis indicadoras do resultado previsto pelo mercado de apostas: vitória, empate ou derrota do time $k$. Sabendo isso, podemos utilizar os dados de torcida dos times para construir para cada município $i$ em um determinado dia $t$ a proporção de 
pessoas sobre o total de habitantes do município recebendo cada tipo de choque. Assim, chamando a proporção de torcedores do time $k$ no município $i$ com relação ao total de habitantes do município de $s_{k, i}$, podemos definir para um determinado município $i$ em um dia $t$ :

(i) positivo $_{i, t}=\sum_{k \in K} s_{k, i}$ pos $_{k, t} \in[0 ; 1]$ : proporção de pessoas recebendo choques emocionais positivos com relação à expectativa racional delas acerca do resultado da partida.

(ii) negativo $_{i, t}=\sum_{k \in K} s_{k, i} n e g_{k, t} \in[0 ; 1]$ : proporção de pessoas recebendo choques emocionais negativos com relação à expectativa racional delas acerca do resultado da partida. ${ }^{10}$

(iii) choque $_{i, t}=$ positivo $_{i, t}-$ negativo $_{i, t} \in[-1 ; 1]$.

De acordo com Wooldridge (2010), o mais comum em um modelo de contagem é que assumamos que

$$
\mathbb{E}[y \mid \mathbf{x}]=\exp (\mathbf{x} \beta)
$$

Finalmente, sendo esse o caso, a interpretação dos parâmetros será exatamente a mesma do que se assumirmos o modelo como sendo log-linear:

$$
\log \left(\operatorname{Viol}_{i, t}\right)=\lambda_{i}+\lambda_{s, m, y}+\lambda x_{t}+\beta c h o q u e_{i, t}
$$

onde Viol $_{i, t}$ representa o número esperado de óbitos causados por violência reportados no município $i$ no dia $t ; \lambda_{i}$ controla características municipais fixas no tempo que influenciem na violência ou futebol (variáveis como o apreço local por futebol, tamanho do município, altitude, distância para o mar); $\lambda_{s, m, y}$ representa um efeito de estado-mês-ano e pode controlar tendências no tempo (captando um efeito de políticas estaduais feitas ao longo do tempo e qualquer tendência no tempo, como desemprego estadual); e $x_{t}$ controla feriados e dias da semana. Dessa forma, o parâmetro $\beta$ terá uma interpretação de semi-elasticidade. Além disso, se $V i o l_{i, t}$ for sempre zero ou algum efeito fixo for sempre zero, a observação não terá relevância para a estimação, sendo descartada (WOOLDRIDGE, 2010). ${ }^{11}$

Além disso, como quero apenas captar um efeito emocional por conta dos resultados das partidas, todas as minhas estimações irão excluir os municípios cuja microrregião está sediando um jogo na data $t$. Isso faz com que meu resultado possa ser interpretado como um efeito emocional ou comportamental dos resultados de partidas, e não um efeito de aglomeração e briga de torcidas no entorno do estádio.

10 Por construção, neutro ${ }_{i, t}^{e m p}=1-\left(\right.$ positive $_{i, t}+$ negative $\left._{i, t}\right)$ e podemos dividir os choques neutros em três tipos: quando um jogo do time $k$ era previsto de ser empate e terminou empatado; quando um jogo era previsto de ser uma derrota do time $k$ e terminou com derrota do time $k$; e quando um jogo era previsto de ser uma vitória do time $k$ e terminou com vitória do time $k$. Usaremos $\sum_{k \in K} s_{k, i} e m p_{k, i} p_{k, t}^{e m p}$ como categoria base e $\sum_{k \in K} s_{k, i} v_{i t} t_{k, i} p_{k, t}^{v i t}$ e $\sum_{k \in K} s_{k, i} d e r_{k, i} p_{k, t}^{\text {der }}$ como controles.

11 Existem 101 uf-mes-anos em que o número de observações é igual a zero. Sendo assim, eu já elimino estas observações antes mesmo de incluir tal efeito fixo de tempo, a fim de manter o número de observações constante ao longo das colunas. Similarmente, farei isso com as heterogeneidades. 
Também chama-se a atenção para o fato de que a variável que mensura os choques possui um formato intensivo, diferente do trabalho de Card e Dahl (2011), que trabalham com uma medida binária. Sendo assim, eu consigo distribuir os choques ao longo das torcidas espalhadas pelo país e captar essas variações ao longo do Brasil afetando a criminalidade.

A Tabela 8 mostra algumas estatísticas das variáveis referentes aos choques emocionais. Podemos ver que elas variam bastante ao longo da amostra, conforme os desvios-padrões são bem maiores do que as médias. Além disso, temos que boa parte dos jogos (cerca de $84 \%$ ) estão associados à choques neutros, o que mostra que o resultado da partida foi aquele previsto pelo mercado de apostas.

Tabela 8: Variáveis de Choques Emocionais

\begin{tabular}{lccccc}
\hline \hline VariávellEstat. & média & d.p. & p10 & p50 & p90 \\
\hline Choque & $-0,023$ & 0,169 & -0.231 & $-0,001$ & 0,141 \\
Positivo & 0,068 & 0,121 & 0,00 & 0,010 & 0,241 \\
Negativo & 0,091 & 0,139 & 0,00 & 0,019 & 0,313 \\
\hline \hline
\end{tabular}

Nota: Elaboração própria.

Portanto, assumindo que o mercado de apostas forneça uma boa predição dos resultados das partidas de futebol ${ }^{12}$, o resultado da partida se torna tão bom quanto se fosse aleatório. Assim, as estimativas de (3.7) se tornam não-viesadas para o efeito causal de um choque pelo resultado da partida. 


\section{Resultados}

\subsection{Especificação Principal}

A Tabela 9 exibe os resultados da estimação da principal especificação do trabalho, dada por (3.7). As colunas (1) a (3) são estimativas de uma regressão de Poisson que conta o número de mortes por agressão para um dia de jogo, sendo que um dia é definido como sendo das 14:00 até às 01:59. Todas as estimativas utilizam erros-padrões clusterizados em grupos de município e utilizam apenas municípios-dia que não sediavam jogos na mesma região metropolitana. Além disso, a amostra está restrita apenas para dias de jogos de futebol, desconsiderando Segundas e Sextas-Feira.

A primeira coluna é a especificação mais simples, onde incluí-se apenas um efeito fixo de município e um de ano. Já na segunda, o efeito temporal passa a ser pelo estado-mês-ano, tornando o modelo mais saturado e controlando por mais alterações em variáveis ligadas ao estado do município. A última coluna repete a anterior mas colocando os controles de dia da semana e feriado, permitindo que o efeito varie ao longo dos diferentes dias da semana. $\mathrm{O}$ resultado estimado para o coeficiente de choque emocional indica que um choque negativo em 1 p.p. aumenta em média $0,08 \%$ o número esperado de óbitos violentos em determinado município-dia. Pelo intervalo de confiança obtido, esse efeito perdura entre algo próximo de $0,15 \%$, valor bem alto e $0,005 \%$, que ainda deve ser considerado um valor alto, visto que é uma variável que mensura óbitos causados por violência.

Esse resultado vai de encontro com o que foi conjecturado anteriormente: choques negativos vão estar associados a emoções ruins, que acabam levando a um comportamento mais violento. Esse resultado vai ao encontro ao obtido por Card e Dahl (2011), já que eles encontram um efeito de cerca de $10 \%$ de choques negativos em violência doméstica. Deve-se lembrar sempre que no caso dos autores citados a variável de choque não possui uma interpretação intensiva, diferente da minha, que varia com o percentual de torcedores recebendo os choques.

\subsection{Robustez e Extensões}

\subsubsection{Heterogeneidades: Gênero e Local}

Ainda seguindo a especificação da coluna (3) da Tabela 9, iremos olhar para mortes por agressão mais específicas. Pelos dados disponibilizados pelo DATASUS, é possível que seja explorado o local de ocorrência do óbito, bem como o sexo da vítima. Assim, posso investigar mais a fundo para tentar encontrar onde o efeito de choques emocionais causados por partidas de futebol está atuando de forma significativa. Todas as colunas seguem a especificação da 
Tabela 9: Especificação Principal

\begin{tabular}{|c|c|c|c|}
\hline $\begin{array}{l}\text { Variável Dependente: } \\
\text { Número de Óbitos por Agressão }\end{array}$ & (1) & (2) & (3) \\
\hline Choque & $\begin{array}{c}-0,0701 \\
(0,0323)^{* * *}\end{array}$ & $\begin{array}{c}-0,0990 \\
(0,0363) * * *\end{array}$ & $\begin{array}{c}-0,0761 \\
(0,0360)^{* *}\end{array}$ \\
\hline EF Município e Ano & $\mathrm{X}$ & $\mathrm{X}$ & $\mathrm{X}$ \\
\hline EF UF-Mes-Ano & & $\mathrm{X}$ & $\mathrm{X}$ \\
\hline Feriados e Dias da Semana & & & $\mathrm{X}$ \\
\hline Obs. & 4.218 .286 & 4.218 .286 & 4.218 .286 \\
\hline \multicolumn{4}{|c|}{$\begin{array}{l}\text { Erros-padrão clusterizados em } 3.401 \text { grupos de municípios estão reportados entre parênteses. } \\
\text { A unidade de observação é ao município-dia. A variável dependente em cada coluna é o número } \\
\text { de óbitos causados por agressões naquele município-dia, sendo que um dia é definido correndo } \\
\text { entre às 14:00 e às 01:59. O choque é uma variável que vale entre }-1 \text { e } 1 \text {, sendo definido como a } \\
\text { diferença entre a proporção de pessoas no município sendo afetadas por choques positivos e a } \\
\text { proporção de pessoas sendo afetadas por choques negativos. Um choque positivo ocorre quando } \\
\text { o time era previsto a perder e não perde ou era previsto a empatar e ganha. Um choque } \\
\text { negativo ocorre de forma análoga. } * p<0.10, * * p<0.05, * * * p<0.001\end{array}$} \\
\hline
\end{tabular}

coluna (3) de 9. No primeiro painel, temos apenas vítimas do sexo masculino, enquanto que no segundo, apenas do sexo feminino. A primeira coluna é referente ao número total de óbitos daquele sexo; a segunda é referente às mortes daquele gênero que ocorreram na rua; e por fim, a terceira é referente às mortes de vítimas daquele gênero que ocorreram em casa.

Podemos notar que no caso de homens, o resultado encontrado diz que existe uma associação negativa entre os choques e o número de óbitos por agressão. Mais precisamente, encontro que um aumento de $1 p$. p. na proporção de indivíduos recebendo choques negativos está associado a um aumento de cerca de $0,14 \%$ no número diário esperado de óbitos masculinos por agressão. Isso mostra que o efeito encontrado na regressão principal vem principalmente por conta de óbitos masculinos.

Além disso, quando olhamos para os óbitos masculinos que ocorrem na rua observamos que o efeito de um choque negativo de 1 p.p. equivale a um aumento de $0,2 \%$ no número esperado de óbitos masculinos na rua por agressão. Se pensarmos em brigas de rua ou confrontos entre torcidas isso pode fazer sentido, mas sempre atentando ao fato de que exclui-se os municípios-dia que estão recebendo jogos na data $t$. Sendo assim, mesmo que seja uma briga entre torcidas, ela está ocorrendo por uma motivação psicológica, e não pelo fato das torcidas estarem se encontrando na região do local da partida.

No caso feminino, observamos que o coeficiente dos choques tem valor positivo mas sem significância, o que indicaria uma relação entre choques positivos e aumento do número de óbitos femininos. Quando olhamos para os locais de ocorrência isso fica evidente. Note que a relação entre choques e óbitos femininos ocorridos na rua é positiva e significante a 5\%: um aumento em 1p.p. nos choques positivos eleva o número esperado de óbitos femininos diários ocorridos na rua em $0,21 \%$. Isso está nos mostrando que de alguma maneira há um efeito de "comemoração" após um resultado positivo e isso acaba gerando mortes femininas na rua. Note que no caso masculino essas mortes diminuíam após um resultado positivo, indicando um comportamento assimétrico nos óbitos masculinos e femininos que ocorrem na rua. 
Além disso, temos um resultado com uma alta magnitude e significância estatística para o caso de óbitos femininos ocorridos dentro de casa. Note que um aumento de $1 p$. $p$. nos choques negativos eleva o número esperado de óbitos femininos ocorridos dentro de casa em cerca de 0, $58 \%$. Podemos comparar o resultado dessa especificação com o resultado de Card e Dahl (2011), já que os mesmos olham para violência doméstica de homens contra mulheres. Na mesma linha do que os autores encontram, o meu resultado indica que há uma forte tendência a violência doméstica de homens contra mulheres em seguida de resultados adversos no futebol.

Tabela 10: Sexo e local dos óbitos

\begin{tabular}{|c|c|c|c|}
\hline $\begin{array}{c}\text { Variável Dependente: } \\
\text { Número de Óbitos por Agressão }\end{array}$ & $\begin{array}{l}\text { Total } \\
(1)\end{array}$ & $\begin{array}{c}\text { Rua } \\
(2)\end{array}$ & $\begin{array}{c}\text { Casa } \\
(3)\end{array}$ \\
\hline \multicolumn{4}{|l|}{ Painel A. Sexo = Masculino } \\
\hline Choque & $\begin{array}{c}-0,137 \\
(0,0271)^{* * *}\end{array}$ & $\begin{array}{c}-0,197 \\
(0,0344)^{* * *}\end{array}$ & $\begin{array}{l}-0,0635 \\
(0,0559)\end{array}$ \\
\hline Obs. & 902.288 & 902.288 & 902.288 \\
\hline \multicolumn{4}{|l|}{ Painel B. Sexo = Feminino } \\
\hline Choque & $\begin{array}{c}0,0425 \\
(0,0283)\end{array}$ & $\begin{array}{c}0,209 \\
(0,0854)^{* *}\end{array}$ & $\begin{array}{c}-0,585 \\
(0,0743)^{* * *}\end{array}$ \\
\hline Obs. & 409.649 & 409.649 & 409.649 \\
\hline EF Município & $\mathrm{X}$ & $\mathrm{X}$ & $X$ \\
\hline EF UF-Mes-Ano & $X$ & $X$ & $\mathrm{X}$ \\
\hline Feriados e Dias da Semana & $X$ & $X$ & $X$ \\
\hline \multicolumn{4}{|c|}{$\begin{array}{l}\text { Erros-padrão clusterizados em grupos de municípios estão reportados entre parênteses. } \\
\text { A unidade de observação é ao município-dia. A variável dependente em cada coluna é o número } \\
\text { de óbitos causados por agressões naquele município-dia, sendo que no Painel A entram apenas óbitos } \\
\text { onde a vítima era do sexo masculino, enquanto que no Painel B, apenas vítimas do sexo feminino. } \\
\text { A coluna (1) incluí todas as mortes para cada sexo; a coluna (2) inclui somente os óbitos onde o } \\
\text { local de ocorrência foi registrado como sendo na rua; e na coluna (3) apenas com o local sendo em } \\
\text { casa. Um dia é definido correndo entre às 14:00 e às } 01: 59 \text {. O choque é uma variável que vale entre } \\
\text {-1 e } 1 \text {, sendo definido como a diferença entre a proporção de pessoas no município sendo afetadas } \\
\text { por choques positivos e a proporção de pessoas sendo afetadas por choques negativos. Um choque } \\
\text { positivo ocorre quando o time era previsto a perder e não perde ou era previsto a empatar e ganha. } \\
\text { Um choque negativo ocorre de forma análoga. * } p<0.10, * * p<0.05, * * * p<0.001 \text {. }\end{array}$} \\
\hline
\end{tabular}

\subsubsection{Morbidade}

Além das informações com relação a óbitos, o DATASUS fornece uma base de dados para internações, através do Sistema de Informações Hospitalares - SIH/SUS. Naturalmente existem muito mais observações para essa base de dados do que para a de mortalidade, visto que é mais comum ocorrerem internações do que mortes. A base segue a mesma classificação da CID-10 que a do SIM, facilitando que a identificação das agressões se dê da mesma maneira. Entretanto, no que diz respeito aos códigos que configuram uma agressão, a base de morbidade fica praticamente por inteira com zeros, mais até do que a de mortalidade, indicando algum problema com o processamento dessa variável.

Sendo assim, a estratégia aqui será utilizar o número agregado de internações, de tal maneira que estou assumindo que as internações por causa relacionadas às agressões estão no meio desse total e tudo mais funciona como um "ruído" na variável. Assumindo que esse 
restante seja ortogonal aos choques, teremos um estimador consistente para o parâmetro dos choques. Seguirei a regressão da coluna (3) em (9), alterando apenas a variável dependente, que agora será o número absoluto de internações em dado município-dia. Além disso é possível abrir para o sexo da pessoa internada, então as colunas (2) e (3) da Tabela (11) serão as internações de homens e mulheres, respectivamente.

Tabela 11: Morbidade total e por sexo

\begin{tabular}{lccc}
\hline \hline \multicolumn{1}{c}{ Variável Dependente: } & Total & Masculino & Feminino \\
Número de Internações Totais & $(1)$ & $(2)$ & $(3)$ \\
\hline Choque & 0,0252 & 0,0176 & 0,0302 \\
& $(0,00457)^{* * *}$ & $(0,00554)^{* * *}$ & $(0,00439)^{* * *}$ \\
\hline EF Município & $\mathrm{X}$ & $\mathrm{X}$ & $\mathrm{X}$ \\
EF UF-Mes-Ano & $\mathrm{X}$ & $\mathrm{X}$ & $\mathrm{X}$ \\
Feriados e Dias da Semana & $\mathrm{X}$ & $\mathrm{X}$ & $\mathrm{X}$ \\
Obs. & 4.160 .747 & 4.160 .747 & 4.160 .747 \\
\hline
\end{tabular}

\footnotetext{
Erros-padrão clusterizados em grupos de municípios estão reportados entre parênteses. A minha unidade de observação é ao município-dia. A variável dependente em cada coluna é o número de internações totais naquele município-dia, sendo que na coluna (1) entram todas as internações, na coluna (2) entram apenas as que sejam de alguem do sexo masculino e na coluna (3) apenas as do sexo feminino. Um dia é definido correndo entre às 14:00 e às 01:59. O choque é uma variável que vale entre -1 e 1 , sendo definido como a diferença entre a proporção de pessoas no município sendo afetadas por choques positivos e a proporção de pessoas sendo afetadas por choques negativos. Um choque positivo ocorre quando o time era previsto a perder e não perde ou era previsto a empatar e ganha. Um choque negativo ocorre de forma análoga. * $p<0.10$, ** $p<0.05$, *** $p<0.001$.
}

O resultado da Tabela (11) indica que choques positivos estão associados de forma significante com aumentos na violência. Pelos resultados estimados, o resultado tem uma magnitude maior para internações femininas. No geral, o resultado indica que um aumento de 1p.p. na proporção de pessoas atingidas por choques positivos eleva o número esperado de internações totais diárias em $0,025 \%$. Devo fazer novamente a ressalva de que no caso de dados de morbidade, estou utilizando todo o tipo de internação, o que pode estar trazendo ruídos que atrapalham os resultados. Além disso, pode ser que internações por conta de violência ligada ao futebol não tenham a mesma interpretação do que as mortes. Por exemplo, internações podem estar mais ligadas à brigas combinadas por torcidas organizadas, enquanto que os óbitos podem estar relacionados à crimes de ódio de fato.

\subsubsection{Teste Placebo - Outras Causas de Óbitos}

Da mesma maneira que construiu-se a variável de óbitos causados por agressões a partir da CID-10, podemos construir outras categorias de óbitos. Se os resultados dos jogos de fato causarem algum choque emocional nas pessoas, então espera-se que esses choques afetem categorias de saúde no curto prazo. Assim, doenças crônicas não devem ser afetadas por choques emocionais causados por resultados de partidas de futebol, já que como discutido antes, esses choques possuem a característica de serem rápidos e transientes.

Sendo assim, aqui utilizaremos outras causas de óbitos para serem explicados pelos choques emocionais. A ideia é que essas causas sejam ortogonais aos choques e, por isso, devem 
indicar resultados sem significância. A Tabela 12 abaixo mostra os resultados, que são replicações da coluna (3) da Tabela 9 mudando apenas a variável dependente. A primeira coluna replica a coluna (3) da especificação principal, enquanto que a coluna (2) considera a variável dependente como sendo $\mathrm{Nao}_{-} \mathrm{Viol}_{i, t}$, onde $\mathrm{Nao}_{-} \mathrm{Viol}_{i, t}$ representa o número de óbitos totais menos o número de óbitos por agressões em dado município $i$ no dia $t$. Como as diferentes causas de óbitos podem ter zeros ao longo dos efeitos fixos, o número de observações varia conforme a causa, com exceção da coluna (2), que é um espelho dos dias da coluna (1) mas com óbitos por causas que não agressões.

Como esperado, temos resultados com nenhuma significância estatística quando comparado aos resultados com a variável de morte por agressão, da coluna (1). Isso ajuda a comprovar a qualidade do modelo, já que ainda que essas outras categorias de óbitos possam assumir o formato de uma Poisson, espera-se que os choques não sejam responsáveis por gerar nenhuma variação importante nelas, pois como discutido anteriormente, estes choques possuem uma característica de serem rápidos, causando consequências no curto prazo.

Tabela 12: Outras causas de morte - Teste Placebo

\begin{tabular}{|c|c|c|c|c|c|c|c|}
\hline & $\begin{array}{c}\text { (1) } \\
\text { Agressões }\end{array}$ & $\begin{array}{c}(2) \\
\text { Não Agressões }\end{array}$ & $\begin{array}{c}(3) \\
\text { Infecciosas }\end{array}$ & $\begin{array}{c}(4) \\
\text { Endócrinas }\end{array}$ & $\begin{array}{c}\text { (5) } \\
\text { Sist. Nervoso }\end{array}$ & $\begin{array}{c}(6) \\
\text { Sist. Digestivo }\end{array}$ & $\begin{array}{c}\text { (7) } \\
\text { Tumorais }\end{array}$ \\
\hline Choque & $\begin{array}{c}-0,0761 \\
(0,0360)^{* *}\end{array}$ & $\begin{array}{r}-0,00575 \\
(0,0141)\end{array}$ & $\begin{array}{l}-0,0153 \\
(0,0336)\end{array}$ & $\begin{array}{l}-0,0230 \\
(0,0268)\end{array}$ & $\begin{array}{c}-0.0448 \\
(0,0279)\end{array}$ & $\begin{array}{l}0,00291 \\
(0,0263)\end{array}$ & $\begin{array}{r}0,00421 \\
(0,0224)\end{array}$ \\
\hline EF Município & $\mathrm{X}$ & $\mathrm{X}$ & $\mathrm{X}$ & $\mathrm{X}$ & $\mathrm{X}$ & $\mathrm{X}$ & $\mathrm{X}$ \\
\hline EF UF-Mes-Ano & $\mathrm{X}$ & $X$ & $X$ & $\mathrm{X}$ & $\mathrm{X}$ & $X$ & $X$ \\
\hline Feriados e Dias da Semana & X & X & X & X & X & X & X \\
\hline Obs. & 4.218 .286 & 4.218 .286 & 4.797 .446 & 5.245 .711 & 5.308 .805 & 4.920 .616 & 5.399 .385 \\
\hline
\end{tabular}

Erros-padrão clusterizados em grupos de municípios estão reportados entre parênteses. A minha unidade de observação é ao município-dia. A variável dependente em cada coluna é o número de internaçôes totais naquele municipio-dia, sendo que na coluna (1) entram todas as internações, na coluna (2) entram apenas as que sejam de alguém do sexo masculino e na coluna (3) apenas as do sexo feminino. Um dia é definido correndo entre às 14:00 e às 01:59. O choque e uma variável que vale entre - 1 e 1 , sendo definido como a diferença entre a proporção de pessoas no município sendo afetadas não perde ou era previsto a empatar e ganha. Um choque negativo ocorre de forma análoga. $* p<0.10$, $* * p<0.05$, $* * * p<0.001$. 



\section{Conclusão}

Nesse trabalho eu estimei o impacto de resultados inesperados de partidas de futebol no comportamento violento dos indivíduos. Para tal, utilizei dados de mercados de apostas que serviram para indicar as probabilidades dos resultados de cada partida: vitória, empate ou derrota. Condicionando a isso, foi possível tratar o resultado da partida como aleatório e criar variáveis de choques inesperados para cada time. A partir da distribuição de torcidas de 64 times ao longo dos municípios do Brasil, foi possível distribuir os choques pelas cidades brasileiras, criando uma medida intensiva da proporção de pessoas por município afetadas por choques emocionais. Junto a isso, utilizei dados de óbitos por causas violentas para cada município e pude captar o efeito causal de choques emocionais em violência, a partir de um modelo de contagem, estimado por uma Regressão de Poisson com dados de 2006 a 2016.

Meu resultado principal indicou uma relação negativa e significante a $5 \%$ entre choques emocionais e violência. Um aumento de $1 p . p$. na proporção de pessoas atingidas por choques emocionais negativos em dado município-dia tem efeito de aumentar o número esperado de óbitos naquele município-dia em $0,08 \%$. Isso significa que se um município tem em média 1 morte violenta por dia, então um aumento de $1 p . p$. na proporção de atingidos por choques negativos é capaz de elevar essa média para 1,008 mortes violentas por dia. Se esse cenário se repetisse por 100 dias no ano, o número esperado de mortes seria de 100,8, isto é, quase uma morte a mais do que no cenário onde não há choque negativo durante esses 100 dias, decorrente de choques emocionais causados por resultados de partidas de futebol.

Além disso, pude captar efeitos fortes quando olhei os dados de óbitos de forma mais heterogênea. Para o número de óbitos com vítimas masculinas e o local da morte sendo a rua, encontrei que um aumento de um ponto percentual na proporção de atingidos por choques negativos é capaz de elevar a média de óbitos em 19.7\%. Quando a vítima é do sexo feminino, choques positivos parecem ter influencia para aumentar a ocorrência de óbitos na rua, enquanto que óbitos ocorrendo em casa são elevados por choques negativos. Este último resultado vai ao encontro da literatura principal, de Card e Dahl (2011), que encontram efeitos de choques negativos por resultados de partidas de futebol americano em violência doméstica. No meu caso, encontro que 1 p.p. a mais na proporção de pessoas recebendo choques negativos em dado município-dia é capaz de explicar um aumento de $58.5 \%$ no número de óbitos com vítimas mulheres e que ocorreram em casa.

Sendo assim, o trabalho vigente apresentou mais resultados para a literatura de Economia do Crime, utilizando um arcabouço comportamental para tal. Em especial, mostrei a relação entre um problema evidente para o caso brasileiro, a violência, e o esporte mais popular do país, o futebol. Sabendo que tal esporte é capaz gerar um comportamento violento nas pessoas, é importante que se dê mais atenção para esse tópico com políticas voltadas à diminuição 
da violência associada ao resultado de partidas.

Algumas análises mais elaboradas podem ser pensadas visando a melhora do estudo. Por exemplo, uma variável que fosse menos concentrada no valor zero poderia gerar resultados mais interessantes, pois teríamos uma melhor captação do efeito causal de choques em violência. Um exemplo seria uma variável como a utilizada em Card e Dahl (2011), a partir de denúncias. Isso esbarra na qualidade da variável ao longo do país, pois pode ocorrer dela não ser mensurada com a mesma qualidade ao longo da base. 


\section{Referências}

BECKER, G. S. Crime and punishment: An economic approach. In: The economic dimensions of crime. [S.1.]: Springer, 1968. p. 13-68. Citado na página 17.

BERTOLI, A. D. Nationalism and conflict: Lessons from international sports. International Studies Quarterly, Oxford University Press, v. 61, n. 4, p. 835-849, 2017. Citado na página 16.

CARD, D.; DAHL, G. B. Family violence and football: The effect of unexpected emotional cues on violent behavior. The Quarterly Journal of Economics, MIT Press, v. 126, n. 1, p. 103-143, 2011. Citado 13 vezes nas páginas 12, 13, 15, 16, 25, 28, 29, 30, 32, 33, 35, 39 e 40.

CARNEIRO, R. D.; SOARES, R. R.; ULYSSEA, G. Local labor market conditions and crime: Evidence from the brazilian trade liberalization. 2015. Citado 3 vezes nas páginas 13,17 e 21 .

CERQUEIRA, D. Mapa dos homicídios ocultos no Brasil. [S.1.], 2013. Citado 2 vezes nas páginas 11 e 18.

CERQUEIRA, D. R. d. C. Causas e consequências do crime no Brasil. [S.1.: s.n.], 2014. Citado 2 vezes nas páginas 13 e 18.

CHIU, W. H.; MADDEN, P. Burglary and income inequality. Journal of Public Economics, Elsevier, v. 69, n. 1, p. 123-141, 1998. Citado na página 17.

CORBI, R. Emotional voters. Retirado de:

<https://sites.google.com/site/raphaelcorbi/research-abstracts>, Working Paper, 2019.

Citado 5 vezes nas páginas 11, 12, 19, 24 e 28.

COSTA, F. et al. Homicides and the age of criminal responsibility in brazil: A density discontinuity approach. 2016. Citado 2 vezes nas páginas 13 e 17.

CROXSON, K.; READE, J. J. Information and efficiency: Goal arrival in soccer betting. The Economic Journal, Wiley Online Library, v. 124, n. 575, p. 62-91, 2014. Citado 2 vezes nas páginas 12 e 24.

DEBNATH, S. et al. Information incorporation in online in-game sports betting markets. In: ACM. Proceedings of the 4th ACM conference on Electronic commerce. [S.1.], 2003. p. 258-259. Citado 3 vezes nas páginas 12, 15 e 24.

DEPETRIS-CHAUVIN, E.; DURANTE, R.; CAMPANTE, F. R. Building nations through shared experiences: Evidence from African football. [S.1.], 2018. Citado na página 16.

DRACA, M.; MACHIN, S.; WITT, R. Panic on the streets of london: Police, crime, and the july 2005 terror attacks. The American Economic Review, American economic association, v. 101, n. 5, p. 2157-2181, 2011. Citado na página 17.

EHRLICH, I. Participation in illegitimate activities: A theoretical and empirical investigation. Journal of political Economy, The University of Chicago Press, v. 81, n. 3, p. 521-565, 1973. Citado na página 17. 
ELSTER, J. Emotions and economic theory. Journal of economic literature, JSTOR, v. 36, n. 1, p. 47-74, 1998. Citado na página 18.

EREN, O.; MOCAN, N. Emotional judges and unlucky juveniles. American Economic Journal: Applied Economics, v. 10, n. 3, p. 171-205, 2018. Citado na página 16.

FAJNZYLBER, P.; LEDERMAN, D.; LOAYZA, N. Inequality and violent crime. The journal of Law and Economics, The University of Chicago Press, v. 45, n. 1, p. 1-39, 2002. Citado na página 17.

FAJNZYLBER, P.; LEDERMAN, D.; LOAYZA, N. What causes violent crime? European Economic Review, Elsevier, v. 46, n. 7, p. 1323-1357, 2002. Citado na página 17.

FLEISHER, B. M. The effect of income on delinquency. The American Economic Review, JSTOR, v. 56, n. 1/2, p. 118-137, 1966. Citado na página 17.

FOLEY, C. F. Welfare payments and crime. The review of Economics and Statistics, MIT Press, v. 93, n. 1, p. 97-112, 2011. Citado na página 17.

FORREST, D.; GODDARD, J.; SIMMONS, R. Odds-setters as forecasters: The case of english football. International journal of forecasting, Elsevier, v. 21, n. 3, p. 551-564, 2005. Citado 2 vezes nas páginas 12 e 24.

GANTZ, W.; BRADLEY, S. D.; WANG, Z. Televised nfl games, the family, and domestic violence. Handbook of sports and media, Lawrence Erlbaum Assoc Incorporated, p. 365-382, 2006. Citado 2 vezes nas páginas 13 e 15.

GLAESER, E. L.; SACERDOTE, B.; SCHEINKMAN, J. A. Crime and social interactions. The Quarterly Journal of Economics, MIT Press, v. 111, n. 2, p. 507-548, 1996. Citado na página 17.

GOULD, E. D.; WEINBERG, B. A.; MUSTARD, D. B. Crime rates and local labor market opportunities in the united states: 1979-1997. The Review of Economics and Statistics, MIT Press, v. 84, n. 1, p. 45-61, 2002. Citado na página 17.

KAHNEMAN, D.; TVERSKY, A. Prospect theory: An analysis of decision under risk. Econometrica: Journal of the econometric society, JSTOR, p. 263-291, 1979. Citado na página 18.

KLICK, J.; TABARROK, A. Using terror alert levels to estimate the effect of police on crime. The Journal of Law and Economics, The University of Chicago Press, v. 48, n. 1, p. 267-279, 2005. Citado na página 17.

KŐSZEGI, B.; RABIN, M. A model of reference-dependent preferences. The Quarterly Journal of Economics, MIT Press, v. 121, n. 4, p. 1133-1165, 2006. Citado 3 vezes nas páginas 12,18 e 29.

LEVITT, S. D. Using Electoral Cycles in Police Hiring to Estimate the Effect of Policeon Crime. [S.1.], 1995. Citado na página 17.

LINDO, J. M.; SIMINSKI, P.; SWENSEN, I. D. College party culture and sexual assault. American Economic Journal: Applied Economics, v. 10, n. 1, p. 236-65, 2018. Citado 2 vezes nas páginas 13 e 16. 
LOCHNER, L. Education, work, and crime: A human capital approach. International Economic Review, Wiley Online Library, v. 45, n. 3, p. 811-843, 2004. Citado na página 17.

LOCHNER, L.; MORETTI, E. The effect of education on crime: Evidence from. 2001. Citado na página 17.

LOEWENSTEIN, G. Out of control: Visceral influences on behavior. Organizational behavior and human decision processes, Elsevier, v. 65, n. 3, p. 272-292, 1996. Citado na página 18.

LOEWENSTEIN, G. Emotions in economic theory and economic behavior. The American Economic Review, JSTOR, v. 90, n. 2, p. 426-432, 2000. Citado 2 vezes nas páginas 12 e 18.

LOOMES, G.; SUGDEN, R. Regret theory: An alternative theory of rational choice under uncertainty. The economic journal, JSTOR, v. 92, n. 368, p. 805-824, 1982. Citado na página 18.

MILLER, T. Q. et al. Imitative violence in the real world: A reanalysis of homicide rates following championship prize fights. Aggressive behavior, Wiley Online Library, v. 17, n. 3, p. 121-134, 1991. Citado na página 16.

NEAL, D. J.; FROMME, K. Hook'em horns and heavy drinking: Alcohol use and collegiate sports. Addictive behaviors, Elsevier, v. 32, n. 11, p. 2681-2693, 2007. Citado na página 15.

NYBERG, H. A statistical test of association football betting market efficiency. 2014. Citado 2 vezes nas páginas 12 e 24 .

PHILLIPS, D. P. The impact of mass media violence on us homicides. American Sociological Review, JSTOR, p. 560-568, 1983. Citado na página 16.

RABIN, M. Incorporating fairness into game theory and economics. The American economic review, JSTOR, p. 1281-1302, 1993. Citado na página 18.

RABIN, M. Psychology and economics. Journal of economic literature, JSTOR, v. 36, n. 1, p. 11-46, 1998. Citado na página 18.

RAPHAEL, S.; WINTER-EBMER, R. Identifying the effect of unemployment on crime. The Journal of Law and Economics, The University of Chicago Press, v. 44, n. 1, p. 259-283, 2001. Citado na página 17.

REES, D. I.; SCHNEPEL, K. T. College football games and crime. Journal of Sports Economics, Sage Publications Sage CA: Los Angeles, CA, v. 10, n. 1, p. 68-87, 2009. Citado 2 vezes nas páginas 13 e 15 .

SACHS, C. J.; CHU, L. D. The association between professional football games and domestic violence in los angeles county. Journal of Interpersonal Violence, Sage Publications, Inc., v. 15, n. 11, p. 1192-1201, 2000. Citado na página 16.

SAUER, R. D. The economics of wagering markets. Journal of economic Literature, JSTOR, v. 36, n. 4, p. 2021-2064, 1998. Citado 2 vezes nas páginas 12 e 24.

SOARES, R. R. Development, crime and punishment: accounting for the international differences in crime rates. Journal of Development Economics, Elsevier, v. 73, n. 1, p. 155-184, 2004. Citado 3 vezes nas páginas 13, 17 e 21. 
STIGLER, G. J. The optimum enforcement of laws. Journal of Political Economy, The University of Chicago Press, v. 78, n. 3, p. 526-536, 1970. Citado na página 17.

TELLA, R. D.; SCHARGRODSKY, E. Do police reduce crime? estimates using the allocation of police forces after a terrorist attack. The American Economic Review, American Economic Association, v. 94, n. 1, p. 115-133, 2004. Citado na página 17.

WOOLDRIDGE, J. M. Econometric analysis of cross section and panel data. [S.1.]: MIT press, 2010. Citado na página 31. 